NBER WORKING PAPER SERIES

\title{
WHAT WE LEARN FROM CHINA'S RISING SHADOW BANKING: EXPLORING THE NEXUS OF MONETARY TIGHTENING AND BANKS' ROLE IN ENTRUSTED LENDING
}

\author{
Kaiji Chen \\ Jue Ren \\ Tao Zha \\ Working Paper 21890 \\ http://www.nber.org/papers/w21890 \\ NATIONAL BUREAU OF ECONOMIC RESEARCH \\ 1050 Massachusetts Avenue \\ Cambridge, MA 02138 \\ January 2016
}

This research is supported in part by the National Natural Science Foundation of China (NNSFC) Grant Numbers 71473168 and 71473169. We thank Marty Eichenbaum, Sergio Rebelo, Richard Rogerson, and Zheng (Michael) Song for helpful discussions. We are grateful to Karen Zhong for her outstanding research assistance. The views expressed herein are those of the authors and do not necessarily reflect those of the Federal Reserve Bank of Atlanta, the Federal Reserve System, or the National Bureau of Economic Research.

NBER working papers are circulated for discussion and comment purposes. They have not been peerreviewed or been subject to the review by the NBER Board of Directors that accompanies official NBER publications.

(C) 2016 by Kaiji Chen, Jue Ren, and Tao Zha. All rights reserved. Short sections of text, not to exceed two paragraphs, may be quoted without explicit permission provided that full credit, including $\mathbb{C}$ notice, is given to the source. 
What We Learn from China's Rising Shadow Banking: Exploring the Nexus of Monetary Tightening and Banks' Role in Entrusted Lending

Kaiji Chen, Jue Ren, and Tao Zha

NBER Working Paper No. 21890

January 2016

JEL No. E02,E5,G11,G12,G28

\begin{abstract}
We argue that China's rising shadow banking was inextricably linked to potential balance-sheet risks in the banking system. We substantiate this argument with three didactic findings: (1) commercial banks in general were prone to engage in channeling risky entrusted loans; (2) shadow banking through entrusted lending masked small banks' exposure to balance-sheet risks; and (3) two well-intended regulations and institutional asymmetry between large and small banks combined to give small banks an incentive to exploit regulatory arbitrage by bringing off-balance-sheet risks into the balance sheet. We reveal these findings by constructing a comprehensive transaction-based loan dataset, providing robust empirical evidence, and developing a theoretical framework to explain the linkages between monetary policy, shadow banking, and traditional banking (the banking system) in China.
\end{abstract}

Kaiji Chen

Department of Economics

Emory University

Atlanta, GA 30322

chen.kaiji@gmail.com

Jue Ren

Emory University

Department of Economics

1602 Fishburne Drive

Atlanta, GA 30322-2240

jue.ren@emory.edu
Tao Zha

Emory University

1602 Fishburne Drive

Atlanta, GA 30322-2240

and Federal Reserve Bank of Atlanta

and also NBER

tzha@emory.edu 
Definition of "regulatory arbitrage:" a practice whereby firms capitalize on loopholes in regulatory systems in order to circumvent unfavorable regulation $[s]$. Investopedia

Shadow banking is defined as "credit intermediation involving entities and activities outside the regular [traditional] banking system or nonbank credit intermediation in short." Financial Stability Board (2013).

The size and rapid growth of shadow banking in China warrants particular attention. Financial Stability Board (2014)

\section{INTRODUCTION}

In the aftermath of the unprecedented stimulus of four trillion RMBs injected by the Chinese government to combat the 2008 financial crisis, the People's Bank of China (PBC) pursued contractionary monetary policy by tightening money supply between 2010 and 2013. The persistent policy of monetary tightening resulted in a simultaneous fall of bank loans and deposits and at the same time a rapid rise of shadow banking (Figures 1 and 2). A principal component of China's shadow banking consists of entrusted loans, a lending activity between nonfinancial firms with commercial banks or nonbank financial companies acting as trustees or middlemen (Figure 3). In particular, the bottom panel of Figure 2 shows that while the total amount of entrusted loans increased during the monetary tightening period of 20102013, its share in the sum of entrusted lending and bank lending more than tripled from $6.6 \%$ in 2010 to $22 \%$ in 2013.

This conspicuous phenomenon has caused concerns of both policymakers and researchers about how the rapid rise of off-balance-sheet entrusted lending would bode ill for China's banking system. By law, commercial banks cannot undertake credit risks associated with entrusted lending. ${ }^{1}$ But the law enacted in May 2000 by the PBC was too general at that time to be implemented in practice until mid-2014. Prior to 2014 the PBC, in a series of "Financial Stability Reports," expressed concerns of spillover risks to the banking system from shadow lending and pointed to a possibility of regulatory arbitrage exploited by banks

\footnotetext{
${ }^{1}$ The concept of "entrusted loans" was officially discussed by the PBC's "General Rules on Loans" issued in 1996. A subsequent law, enacted in May 2000, explicitly states that commercial banks as trustees in entrusted loans can only receive commission fees and cannot undertake credit risks.
} 

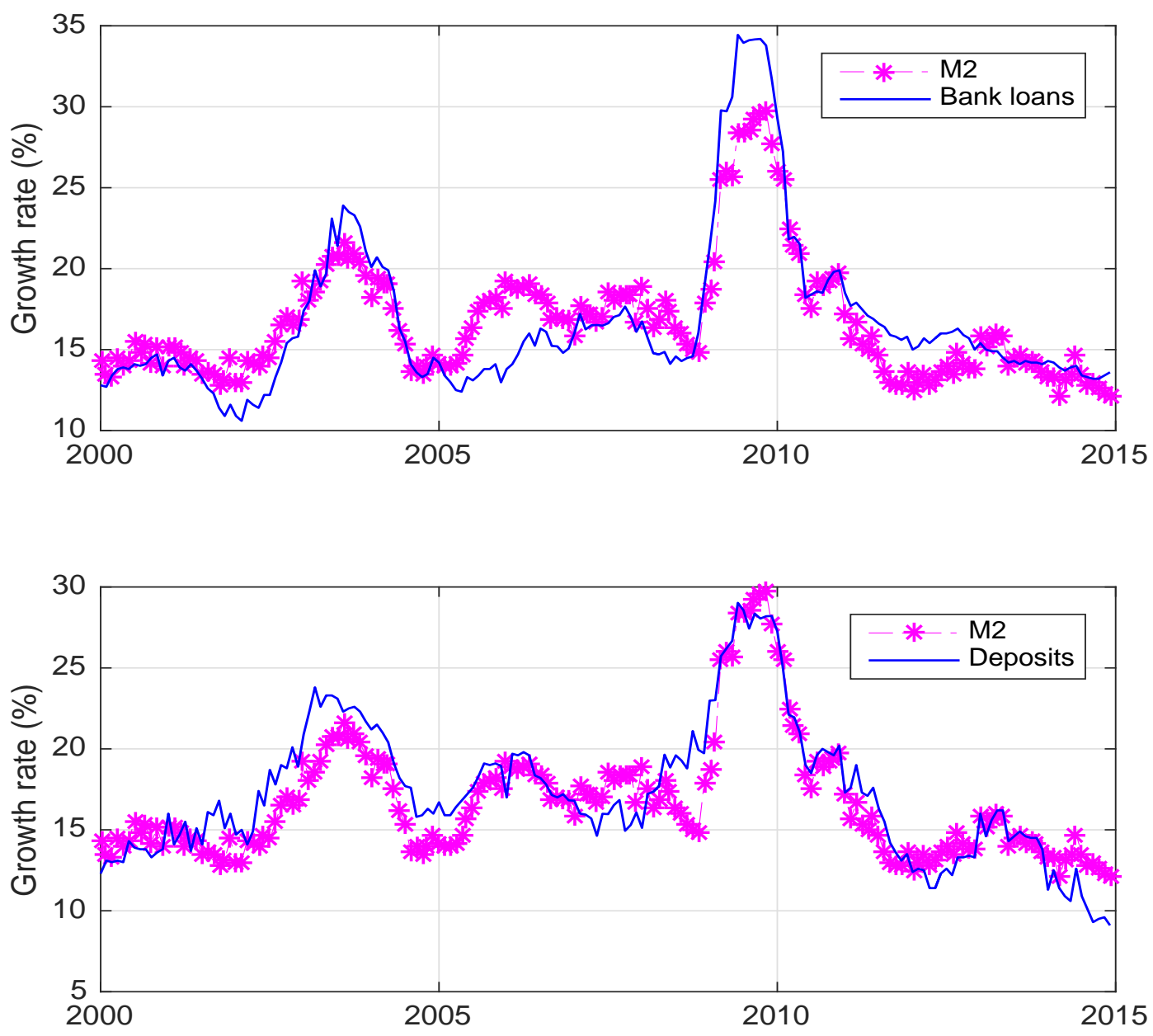

FIGURE 1. Growth rates (year over year) of monetary aggregates, bank loans, and bank deposits. Data sources: PBC and CEIC (the database provided by China Economic Information Center, now belonging to the Euromoney Institutional Investor Company).

to take on such risks. ${ }^{2}$ The report, however, did not identify which specific regulations gave banks an incentive to exploit regulatory arbitrage. And there has been little academic research that addresses this broad and important issue.

This paper is to fill this vacuum in the literature and study related issues on the linkages between monetary policy, shadow banking, and traditional banking. To identify banking regulatory loopholes and which types of banks that exploited these loopholes and to assess what kind of consequences such an exploitation brought into the banking system, we take

\footnotetext{
${ }^{2}$ See, for example, page 174 in the PBC's 2013 Financial Stability Report. Similar concerns about regulatory arbitrage were expressed by the Chinese Banking Regulatory Commission in its 9 May 2011 regulation and the State Council in its 10 December 2013 notice.
} 

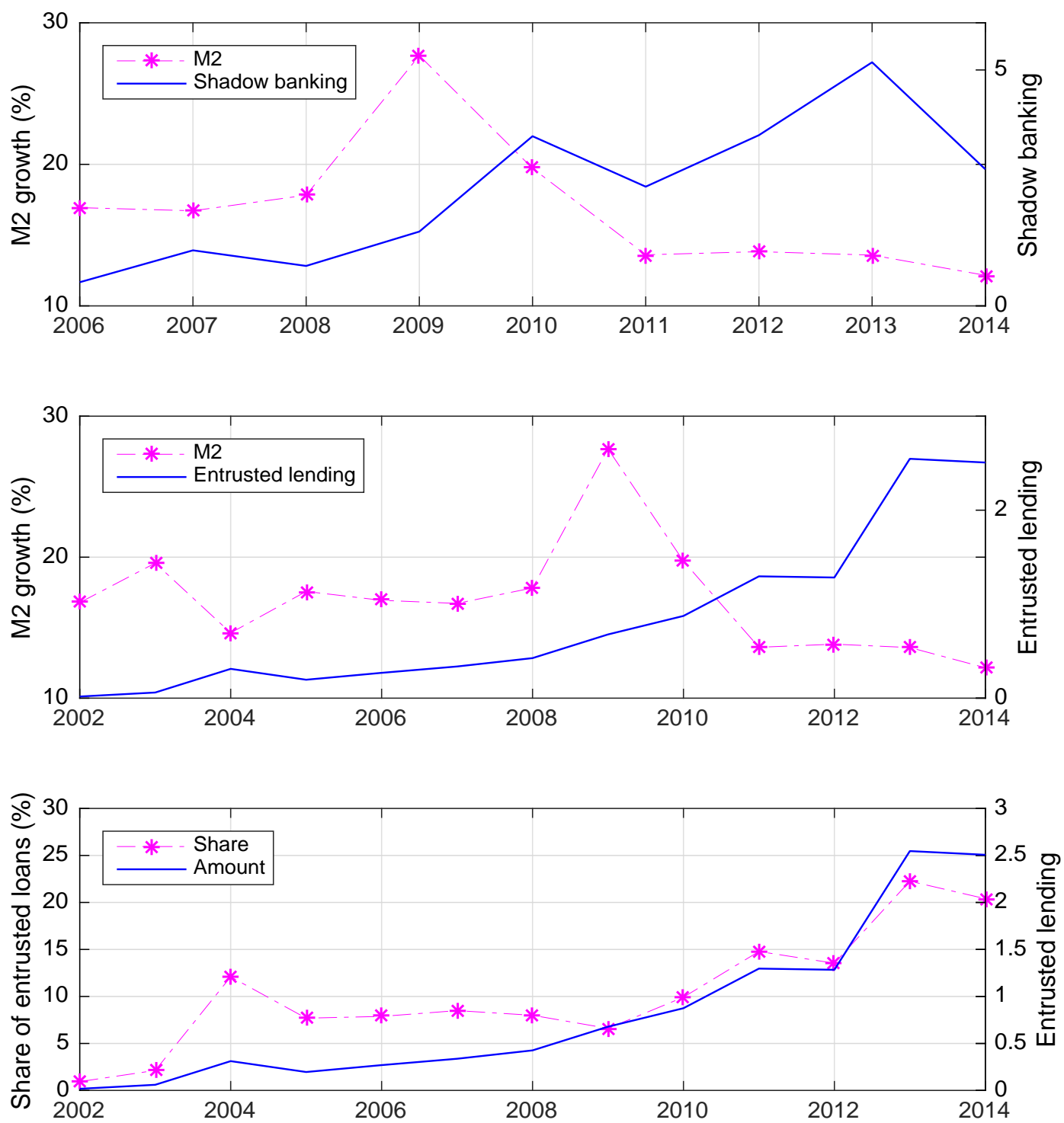

FIGURE 2. M2 growth and the rise of shadow banking and entrusted lending (in trillion RMB). Entrusted lending is one principal component of shadow banking. Both shadow banking and entrusted lending are newly originated loans. The share of entrusted loans is the share of the entrusted-lending amount in the sum of entrusted lending and bank lending, where bank lending is measured by newly originated bank loans as well. Data sources: PBC and CEIC.

as given the macroeconomic trends of monetary aggregates and entrusted loans displayed by Figures 1 and 2 and focus on two distinct but related questions: (a) were Chinese banks prone to engage in channeling risky entrusted loans in response to monetary policy changes and (b) if so, how did the risk of shadow loans spill over into the banking system's balance sheet? 


\section{Lenders (Firm A) $\longrightarrow$ Trustees $\longrightarrow$ Borrowers (firm B)}

Figure 3. A basic structure of entrusted loans as commonly understood. Trustees include banks and nonbank financial companies that facilitate entrusted loans.

To frame an answer to these two questions in a coherent way, we provide both empirical and theoretical analyses. The empirical analysis is based on the transaction-based loan data constructed by us and the theoretical framework is grounded in China's unique institutional characteristics.

We complete these analyses with four distinct but related contributions. First, we manually collect and construct a comprehensive micro transaction-based dataset on entrusted loans by merging entrusted-loan announcements (the most important source), nonfinancial firms' annual reports, and banks' annual reports, all downloaded from the WIND database (the data information system created by the Shanghai-based company called WIND Co. Ltd., the Chinese version of Bloomberg). We verify our dataset with various Financial Stability Reports published by the PBC. The Bankscope database (a comprehensive, global database of banks financial statements, ratings, and intelligence, provided by Bureau Van Dijk) is also used for obtaining other balance-sheet information such as capital adequacy ratio. We read through more than a thousand relevant announcements line by line and cross-check the data from different sources to decipher the reporting nuances in the Chinese language, eliminate redundant and duplicated observations, and obtain accurate and comprehensive data for entrusted lending facilitated by banks and nonbank trustees. During this construction process that has taken us several years to complete and is still continuing to refine the dataset, we identify lending firms, borrowing firms, and, most important of all, trustees that facilitated entrusted lending between nonfinancial firms. Our subsequent empirical and theoretical work shows how and why, among different types of trustees, banks behaved differently from nonbank trustees and how and why, among banks, small banks behaved differently from large banks. Our data sample begins in 2007 and ends in 2013 with over 750 unique observations. China's shadow banking began in 2007, accelerated during the period of monetary tightening after the government's 2008-2009 economic stimulus, and was then heavily regulated from mid-2014 forward. Throughout 2014-2015, the Chinese Banking 
Regulatory Commission (CBRC) first issued and then implemented new regulations specifically prohibiting banks from taking on credit risks through entrusted lending. Thus, the period of 2007-2013 is a critical period for us to understand the issues raised above.

With the constructed micro data, we establish, as a second contribution, empirical evidence of whether banks are prone to engage in risky entrusted lending. The task is challenging because one must identify banks' risk-taking behavior from the data. We address this identification issue by using two instruments. One is to use the transaction-based observations on nonbank trustees to distinguish banks' behavior in our difference-in-difference approach. Since monetary and banking regulations apply to the banking system only, this instrument allows us to isolate the effect of monetary tightening on banks' willingness to facilitate entrusted lending. We show that without this instrument the regressions would underestimate such an effect.

The other instrument relates to different types (qualities) of loans: one type is risky and the other one is not. We use the loan data on the risky type as an instrument. By controlling for the time effect and the industry-fixed effect, we estimate a large number of regressions with double or triple interactions to determine different roles played by banks in channeling entrusted loans to the risky industry. By the risky industry we mean a combination of the real estate industry and 18 overcapacity industries identified by China's Ministry of Industry and Information Technology. We find that during the period of monetary tightening, banks facilitated more entrusted loans than nonbank trustees. Among banks, small banks tended to funnel more entrusted loans to the risky industry than large banks in response to monetary contractions. ${ }^{3}$ By contrast, the estimation shows that monetary tightening has an inconsequential effect on nonbank trustees' willingness to facilitating risky entrusted loans.

Third, we provide a detailed discussion of China's unique institutional characteristics that underlay banks' incentives to channel entrusted loans, especially risky ones, during the period of monetary tightening. One unique feature of monetary policy in China is to use monetary aggregates as a major target to stabilize macroeconomic fluctuations. Interest

\footnotetext{
${ }^{3}$ Large banks, controlled and protected by the state, are the Industrial and Commercial Bank of China, the Bank of China, the Construction Bank of China, the Agricultural Bank of China, and the Bank of Communications. The Bank of Communications, initially listed in the Hong Kong Stock Exchange, has officially become the fifth largest state-owned bank since May 16, 2006. The other commercial banks are small relative to these large five banks, including among others China CITIC Bank, China Everbright Bank, China Merchants Bank, Shanghai Pudong Development Bank, the Industrial Bank of China, and the Bank of Beijing.
} 
rates were not a major macroeconomic stabilizer until 2014 at the earliest. The main purpose of monetary policy in China has been to control credits and deposits in the banking system. Monetary aggregates such as M2 are a primary target to accomplish this task. As is evident in Figure 1, growth in money supply moved in tandem with growth in bank credits and deposits. In addition to monetary policy, there were two unique regulatory restrictions specific to China's banking system: the legal ceiling on the ratio of loans to deposits (LDR) imposed by the PBC on each commercial bank, which we call the "LDR regulation," and the regulation prohibiting commercial banks from expanding bank loans to the risky industry, which we call the "safe-loan regulation."

Monetary tightening gave banks a stronger incentive to circumvent these regulations. As the PBC tightened money supply, bank deposits fell. The pressure built up on deposit shortages, which exposed banks to the risk of violating the LDR regulation. ${ }^{4}$ Chinese small banks incurred higher costs, implicit or explicit, than large banks to acquire additional deposits when facing random deposit shortfalls. As a result, the LDR and safe-loan regulations, together with institutional asymmetry between large and small banks in coping with unexpected deposit shortfalls, gave small banks an incentive to take advantage of regulatory arbitrage. One effective way for regulatory arbitrage is to increase nonloan investment that was not subject to the LDR and safe-loan regulations and at the same time reduce bank loans that were subject to these two regulations. More important is the fact that such nonloan investment is on the asset side of bank balance sheet. One principal component of nonloan investment was in the form of the beneficiary rights of entrusted loans funneled by the banks, which we call "entrusted rights" for short. As we show in Section V, nonloan investment was significantly correlated with entrusted lending for small banks, but not for large banks, during the period of a simultaneous fall in monetary aggregates and a rapid rise in entrusted lending (Figure 2). What was supposed to be the risk outside the banking system showed up on small banks' balance sheet. Consequently, shadow banking was used by small banks to mask credit risks in the banking system by cleverly circumventing the regulatory restrictions.

To place our empirical findings and China's institutional features in a coherent conceptual framework, we develop a theory of banks' optimal portfolio choice subject to China's unique LDR and safe-loan regulations. The theoretical model, constituting a fourth contribution of

\footnotetext{
${ }^{4}$ For detailed discussions of this regulation risk, see Sections V and VI.5 as well as various "Financial Stability Reports" published by the PBC.
} 
the paper, is designed to be tractable for obtaining intuitive results. We show that when the deposit withdrawal risk increases as a result of monetary tightening, the small bank will optimally increase investment in risky assets that are not counted as part of bank loans and thus not subject to the LDR and safe-loan regulations. An increase in nonloan risky investment effectively offsets the extra costs of meeting deposit shortfalls faced by the small bank to satisfy the LDR regulation. The small bank, therefore, kills two birds with one stone. The stone is an increase of nonloan risky investment, one bird is the safe-loan regulation, and the other bird is the LDR regulation. Our theoretical predictions are consistent with our empirical findings. A novel feature of our theory is that the small bank exploits regulatory arbitrage by trading off the regulation risk of bank loans with the default risk of shadow loans, a unique Chinese institutional characteristic.

All four elements - micro data, empirical evidence, institutional characteristics, and theoryare woven together as a composite framework for understanding banks' risk-taking incentive that underlay banks' active participation in shadow banking and the resultant financial risk that may have endangered the health of China's banking system. Our empirical and theoretical findings offer one of the didactic lessons: how well-intended banking regulations can generate a perverse incentive for banks to take advantage of regulatory arbitrage. The well-intended regulations were designed to prohibit banks from directly engaging in risky bank loans on the one hand restrict the amount of bank loans by the LDR ceiling on the other hand. Our study demonstrates that these well-intended regulations had an unintended consequence: they encouraged Chinese small banks to bring supposed off-balance-sheet risks into on-balance-sheet risks during the period of monetary tightening through the means of risky entrusted lending.

The rest of the paper is organized as follows. Section II reviews the literature complementary to our paper. Section III details how our transaction-based data are constructed. Section IV provides robust empirical evidence on banks' risk-taking behavior in channeling entrusted loans. Section V presents the institutional details relevant to our empirical and theoretical analyses. Section VI develops our theory and offers its implications and predictions. Section VII concludes the paper.

\section{Literature REVIEW}

There are several strands of literature that are relevant to our paper. One strand of literature is theoretical, represented by Bianchi and Bigio (2014) who develop a theoretical 
framework for evaluating the tradeoff faced by the ex-ante homogeneous bank between profiting from more loans on the one hand incurring the liquidity risk exposure associated with a potential reserve shortfall on the other hand. ${ }^{5}$ Our theoretical work builds on Bianchi and Bigio (2014) but with unique Chinese institutional characteristics. In particular, bank loans are subject not to reserve shortfalls but to deposit shortfalls during the period of monetary tightening. The problem facing Chinese banks, especially small banks, is not a reserve requirement, but the LDR ceiling constraint and the safe-loan regulation imposed by the PBC. Another new feature of our theoretical model is that Chinese banks face a tradeoff between the regulation risk associated with bank loans and the default risk associated with shadow loans through risky nonloan investment.

Another strand of literature is empirical, represented by Jiménez, Ongena, Peydró, and Saurina (2014) who utilize the Spanish loan data to study the effect of monetary policy expansion on the supply of traditional bank loans to risky firms. They introduce triple interactions among monetary policy, bank characteristics, and borrower characteristics into regressions of the credit supply. Our paper, by contrast, studies the bank's risk-taking behavior in facilitating shadow loans during the period of monetary tightening. More important are our results suggesting that the reason for the risk-taking behavior of banks in China is sharply different from that in the developed countries because China's unique institutional background plays a critical role in the close relationships between monetary tightening, bank loans, and shadow loans.

Both our empirical and theoretical findings contribute to the growing literature on China's shadow banking. First, some of our findings are complementary to Hachem and Song (2015). Both our work and their paper highlight China's regulations on banks' LDRs as a key to understanding the rapid growth of China's shadow banking activity. Hachem and Song (2015) focus on the effect of the LDR constraint on the liabilities of banks' balance sheet, via banks' issuance of so-called "wealth management products" (WMPs) as an alternative to deposits to circumvent such a regulation. Accordingly, the shadow-banking risk in Hachem and Song (2015) is a maturity mismatch as short-maturity WMPs are used to finance longterm loans. By contrast, our study on entrusted lending and its linkage to risky nonloan assets on banks' balance sheet shed light on the impact of China's rising shadow banking

\footnotetext{
${ }^{5}$ In other banking works such as Gertler and Kiyotaki (2010) and Christiano and Ikeda (2013), shocks to the bank equity, coupled with the credit constraint, affect the supply of bank loans, as these shocks exacerbate the incentive problem of banks. Accordingly, the focus of those papers is to explain the effects of policies to recapitalize the banks.
} 
from the viewpoint of the asset side of banks' balance sheet. Our empirical findings point to the default risk of such shadow loans that banks may choose to bear as a tradeoff against the regulation risk stemming from both the LDR ceiling and the safe-loan law.

Several recent empirical papers explore the micro-level entrusted loan data from a perspective of firms. For example, He, Lu, and Ongena (2015) investigate the reaction of stock prices of both issuing and receiving firms to an entrusted-loan announcement. Allen, Qian, $\mathrm{Tu}$, and $\mathrm{Yu}$ (2015) explore which types of lending firms tend to make entrusted loans and their motives in making affiliated and non-affiliated entrusted loans. Qian and Li (2013) provide an analysis of entrusted lending as an alternative way of external funding to bank loans when the borrower and the lender have an affiliation relationship. None of these papers, however, study the role of banks in facilitating entrusted loans and the importance of the unique institutional background behind banks' ultimate incentive for partaking in such shadow lending. ${ }^{6}$

Our paper also contributes to the literature on monetary transmission mechanism. Prior to Jiménez, Ongena, Peydró, and Saurina (2014), Kashyap and Stein (2000) are the first to use the bank-level data to identify the effect of monetary policy on credit supply via banks' liquidity position. Subsequently, Ivashina and Scharfstein (2010) use the syndicated-loan data to understand the effect of the 2008 financial crisis on the supply of bank credit to corporations with different exposures to drawdown risks of credit lines. Like Ivashina and Scharfstein (2010), monetary tightening also has two effects in our paper: a direct effect on reduction of deposits committed by firms and households and an indirect effect on the rise of deposit withdrawal risk. Various government and financial reports document both effects during the period of monetary tightening in 2010-2013. Unlike Ivashina and Scharfstein (2010), bank loans in China were relatively safe as the government either implicitly guaranteed these loans or explicitly prohibited risk-taking loans through its strict regulations. A more serious problem lay in shadow loans that were not subject to strict regulations until 2014. Our paper takes a first step in identifying and quantifying the effect of monetary policy contractions on banks' roles in risky entrusted lending during the period of monetary contractions between 2010 to 2013.

\footnotetext{
${ }^{6}$ Various non-academic policy articles argue that the development of shadow banking in China might bear risks to China's financial system. See, for example, Adrian, Ashcraft, and Cetorelli (2013), Elliott and Yu (2015), the 2011 "Global Research Report" of the HSBC, the 2013 Nomura Global Report on "China: Rising Risks of Financial Crisis," the 2014 "Half-Yearly Monetary and Financial Stability Report" of the Hong Kong Monetary Authority (HKMA), and various PBC reports.
} 
More generally, our paper identifies the institutional asymmetry between large and small banks in costs of acquiring additional deposits in the event of unexpected deposit shortfalls. The institutional asymmetry, together with the LDR and safe-loan regulations, gave a perverse incentive for small banks to exploit regulatory arbitrage by bringing risky shadow loans into the balance sheet under a different asset category that was not subject to the LDR and safe-loan regulations. Furthermore, our paper identifies a mechanism in which small banks brought off-balance-sheet risks into the balance sheet. These analyses shed light on the importance of designing a comprehensive package of regulations that would lead to right incentives for banks to make loans or invest in risky assets.

\section{DATA CONSTRUCTION AND DESCRIPTION}

The micro loan data used in this paper consist of transactions of entrusted loans between Chinese firms, facilitated by trustees as middlemen. The sample is from 2007 to 2013. We read various data sources line by line and combine them to ensure the accuracy of our manually constructed dataset. In this section, we first describe how we construct our transaction-based dataset and then provide relevant descriptive statistics.

III.1. Data construction. We first collect all the pdf files of raw entrusted-loan announcements made by listed firms in China. Listed firms are those that issue A-share stocks to the public and thus are listed in China's stock exchanges. Chinese law requires listed lending firms to make public announcements about each entrusted-loan transaction. Listed borrowing firms could choose to make announcements but are not required by law. In 2005 China Securities Law Article 67 also requires all listed firms to announce major events which may have influenced their stock prices. ${ }^{7}$ In 2011, according to Article 2 of the CSRC's "Rules for Information Disclosure by Companies Offering Securities to the Public," listed firms have responsibility to disclose all entrusted-loan transactions. Moreover, according to two disclosure memoranda provided by the Shenzhen Stock Exchange in 2011, a listed company must disclose information of entrusted loans as long as its subsidiary firm is a lender of entrusted loans, even if the company itself is not a direct lender.

A raw announcement made for each transaction concerns either a newly originated loan or a repaid loan. Information in each raw announcement contains the names of both lender and borrower, the amount transacted, and relevant financial information if applicable. For

\footnotetext{
${ }^{7}$ The Chinese Securities Regulatory Commission (CSRC) publishes such documents at http://www . sac.net.cn/flgz/flfg/201501/t20150107_115050.html.
} 
each year between 2010 and 2013 , we verify the number of our collected raw announcements against the number published by the PBC's 2011-2014 Financial Stability Reports (the reports publish the numbers in the previous years). Figure 4 plots the numbers of transactions. One can see from the figure that the discrepancy between our data and the numbers published by the Financial Stability Reports is of little importance. Although both our data source and the PBC's data source are from WIND, at the time when the PBC reported the number of announcements, some companies had not yet made announcements until a later year. Some of these delayed announcements are included in our data collection, which may explain part of this inconsequential discrepancy.

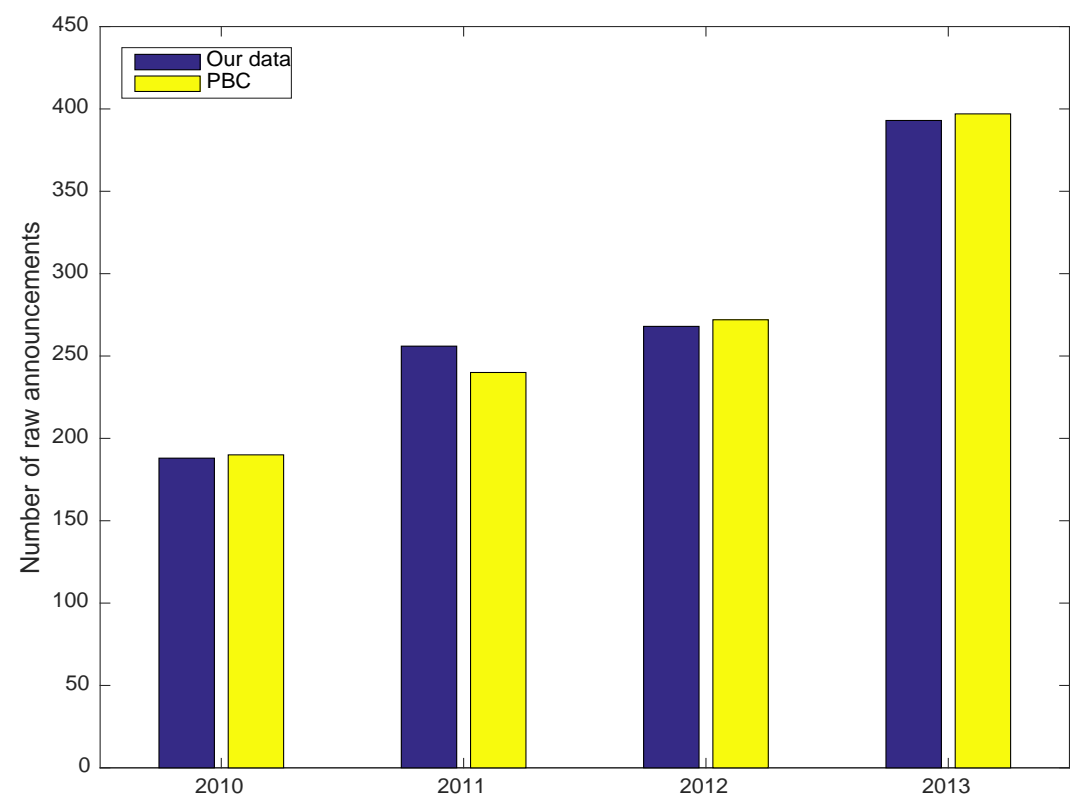

FiguRE 4. Number of raw announcements we collect versus number published by the PBC's Financial Stability Reports. Data source: WIND

One main reason we must read raw announcements and other relevant documents line by line is that there were often multiple announcements made by an individual lender for the same transaction. In such cases, we manually combine these raw announcements into one announcement. Some announcements were for repayment of entrusted loans. To avoid double counting, we drop those announcements if the same transaction was recorded in previous announcements. Another reason for reading through raw announcements is to obtain the trustee information as much as possible. For some raw announcements, however, the trustee information was missing. In this case we search the annual reports of listed nonfinancial companies that documented the same transactions for the trustee information missing in those announcements. A third reason for reading through raw announcements relates 
to the nuances of the Chinese language in expressing how the transaction of an entrusted loan was conducted. For some announcements, the amount of a particular entrusted loan was planned but never executed or executed with a different amount in a later announcement. During the loan planning stage, the name of the trustee was often omitted from an announcement. If we had not been careful about these announcements, we would have exaggerated the number and the amount of entrused loans collected. A fourth reason is that we must remove announcements about loans that had already been paid to avoid duplication. The announcements organized this way are the ones we use for the paper and we call them "announcements" rather than "raw announcements" with the understanding that those announcements have been already cleaned up from raw announcements. The total number of raw announcements is 1279. The number of (cleaned-up) announcements is 778 .

Our data construction involves extracting the transaction data, manually, from our cleanedup announcements of new loans. For each announcement, we record the lender and the borrower. Because the same transaction may be announced by both lender and borrower, two announcements may correspond to only one transaction. In such cases we manually compare both announcements to ascertain the accuracy of our processed data set. ${ }^{8}$ After the comparison, we merge the two announcements for the same transaction into one unique observation. It turns out that the number of such announcements is only three. Subtracting these three double-counted announcements give us 775 unique observations. The timing of the observation corresponds to the exact timing of the transaction and thus does not necessarily correspond to the time when an announcement was made. The transaction data constructed from these unique observations are used for our empirical analysis.

The micro transaction-based data of entrusted loans we have collected differ from the aggregate data in several important aspects. First, the aggregate series includes loans between nonfinancial firms as well as four other categories: (i) cash management, (ii) provident funds for housing, (iii) entrusted loans financed by WMPs, and (iv) syndicated loans. In a strict sense, these four other categories are not loans entrusted from one nonfinancial firm to another. ${ }^{9}$ Indeed, some of these categories, such as cash management and syndicated loans, were re-classified and disqualified as entrusted loans in 2015. According to a 2015 CBRC report, moreover, housing provident funds are not subject to the CBRC regulations

\footnotetext{
${ }^{8}$ We find that the lender's announcement typically contains more information than the borrower's.

${ }^{9}$ Cash management refers to an outsourcing to a bank by a conglomerate to manage short-term funds across its own subsidiaries.
} 
on activities of commercial banks that facilitate entrusted loans. Second, announcements are made by listed firms while aggregate entrusted loans may include those transacted between nonlisted firms. Third, aggregate data on entrusted loans may include those repaid already and the same transactions that were reported multiple times. Fourth, it is unclear whether the timing of aggregate entrusted loans corresponds to the time when the loans were reported or the time when actual transactions took place. Despite these differences, however, the aggregate series calculated from our micro data has a similar growth pattern as the macro aggregate data provided by the CEIC (the average growth rate is $40.55 \%$ for our micro data and $35.75 \%$ for CEIC macro data between 2007 and 2013 and $33.77 \%$ for ours and $32.57 \%$ for CEIC between 2010 and 2013).

III.2. Data description and other data sources. This section provides key banking characteristics of our constructed transaction data from 2007 to 2013 and describes how our data are merged with other data sources.

III.2.1. Data observations and characteristics. Table 1 shows how we arrive at the number of unique observations without duplicated announcements. Thus, the number of unique observations must equal the sum of "NLA" and "NBA" minus "NLABA" (the number of duplications). Clearly, the number of announcements made by lenders was considerably greater than the number of announcements made by borrowers, a fact that is consistent with the legal requirement that listed lending firms must reveal entrusted-loan transactions.

Table 2 shows a breakdown of transactions by different types of trustees and different types of loans. Affiliated loans involve both lending and borrowing firms within the same conglomerate. While most entrusted loans facilitated by nonbank trustees were affiliated ones, a majority of affiliated loans were channeled by banks, a fact that is not well known. As one can see from the table, no matter whether entrusted loans were affiliated or not, small banks facilitated more transactions than large banks, and large banks faciliated more transactions than nonbank trustees. Thus, banks played a critical role in facilitating both affiliated and non-affiliated entrusted loans.

Small banks accounted for the largest fraction of both loan transactions and loan volume (amount). Table 3 shows that the number of entrusted-loan transactions facilitated by small banks took $48 \%$ of the total number and the amount of entrusted loans $40 \%$ of the total amount. Thus, small banks played a special role in funneling entrusted loans. 
TABLE 1. Number of announcements made by lenders and borrowers

\begin{tabular}{|c||c|c|c|c|}
\hline Description & NLA & NBA & NLABA & Total \\
\hline Number of observations & 644 & 134 & -3 & 775 \\
\hline
\end{tabular}

Note. NLA: number of lenders' announcements; NBA: number of borrowers' announcements; NLABA: number of the same transactions announced by both lenders and borrowers.

TABLE 2. A breakdown of the total number of transactions by types of trustees and types of loans

\begin{tabular}{|c||c|c|c|c|}
\hline Description & NBTs & Large banks & Small banks & Total \\
\hline Non-affiliated loans & 3 & 87 & 135 & 225 \\
Affiliated loans & 122 & 188 & 240 & 550 \\
\hline Total & 125 & 275 & 375 & 775 \\
\hline
\end{tabular}

Note. NBTs: nonbank trustees.

TABLE 3. Proportions (\%) of loan transactions and loan volume according to different types of trustees

\begin{tabular}{|c||c|c|c|c|}
\hline Description & NBTs & Large banks & Small banks & Total \\
\hline Number of transactions & 16.13 & 35.48 & 48.39 & 100 \\
Loan volume & 24.33 & 34.85 & 40.82 & 100 \\
\hline
\end{tabular}

Note. NBTs: nonbank trustees.

III.2.2. Other data sources. In addition to the constructed transaction data, our study uses other data sources. One main other source to which our transaction data are bridged is banks' balance-sheet information from WIND, which allows us to compute the correlation of entrusted lending off balance sheet and risky investment on balance sheet as discussed in Section V.4. WIND contains balance-sheet information of listed banks. When an announced transaction identifies the name of the bank, we link the transaction to the WIND information of this bank. For balance-sheet information of nonlisted banks, we resort to Bankscope. If the balance-sheet information of a particular bank is unavailable from WIND or Bankscope, we search the website for this particular bank to obtain its annual reports. There are a total of 19 banks listed in the Hongkong, Shenzhen, or Shanghai Exchange. In 2013, these 19 banks possessed $70 \%$ of the total assets of 164 banks and nonbank trustees covered by Bankscope. The five large banks and most joint-stock commercial banks were listed during our sample 
period. Some local banks or foreign banks are not covered by Bankscope. These missing banks are usually very small and most likely unlisted. ${ }^{10}$ Bankscope contains information related to capital adequacy ratio and loan-to-deposit ratio; WIND contains information related to excess reserves and other nonloan asset categories.

Annual reports (in pdf form) of listed nonfinancial companies as well as listed banks are manually collected from the WIND dataset. The WIND dataset also contains some financial information of both banks and nonfinancial firms, which helps expedite the process of data collection and organization as well as verify the accuracy of our constructed dataset.

The annual report of a listed nonfinancial company may also contain information about entrusted loans, as used by Allen, Qian, Tu, and Yu (2015). The scope of our paper, however, compels us to use information contained in announcements of entrusted loans for several reasons. First, announcements are more likely to disclose names of the banks than annual reports. Of all the transactions in our sample, most facilitating trustees are identified by announcements except 52 banks and one nonbank trustee we identify with annual reports. Since our focus is on the role of banks in transacting entrusted loans, the bank information is of vital importance. Second, for a particular transaction, annual reports may contain information about the amount of outstanding entrusted loans, instead of the amount of newly originated loans. For example, in a 2010 announcement of "Shandong Chenming Paper Holdings Limited," the total amount of entrusted loans worth 500 million RMB was recorded; after this loan transaction, there were no additional entrusted loans made in 2010 and 2011 by this company and thus there were no more announcements from the company during this period. In both 2010 and 2011 annual reports of the same company, it listed entrusted loans to its subsidiary "Jiangxi Chenming Paper Holdings Limited" with the total amount of 500 million RMB, because the outstanding loans had maturity dates beyond 2011 . Without the knowledge of maturity dates, one would have double counted the number of actual transactions as well as the total amount of newly issued loans.

\section{EMPIRICAL FINDINGS}

In this section we undertake the task of establishing evidence of the risk-taking behavior of Chinese banks in channeling entrusted loans during the period of monetary contractions. With our constructed micro dataset, we use two instruments to identify such a risk-taking

\footnotetext{
${ }^{10}$ In 2015, China had 3 policy banks, 5 state-owned banks, 12 joint-stock banks, 120 local banks, and 75 foreign banks. Policy banks are simply the arms of the PBC for carrying out monetary policy operations and thus are treated as part of the central bank, not commercial banks.
} 
behavior. One instrument is the data on entrusted lending facilitated by nonbank trustees in our difference-in-difference approach. The other instrument is the data on entrusted lending to the risky industry. The risky industry is identified according to Number 111 of the "2010 Manufacturing Industry Announcement" issued by the Ministry of Industry and Information Technology. The industry includes real estate, iron, steel, coke, ferroalloy, calcium carbide, aluminum, copper smelting, lead smelting, zinc smelting, cement, glass, paper, alcohol, monosodium glutamate, citric acid, tanning, dyeing, and chemical fiber-a total of 19 industries.

We accomplish the task by answering the following questions sequentially. (1) Relative to nonbank trustees, did banks play an important role in entrusted lending during the period of monetary tightening? (2) What type of banks, small or large, was more likely to be engaged in facilitating entrusted loans? and (3) What type of loans, risky or non-risky, did such banks tend to facilitate? Prior to answering these questions, we first document the relationships among risky entrusted loans, their maturities, and their interest rates. These relationships are essential to one of the assumptions in our theoretic model developed in Section VI.

IV.1. Maturities and lending rates of entrusted loans. Each loan transaction is uniquely determined by a quadruple index $s=(t, i, b, j)$, where $t$ represents the year in which the transaction takes place, $i$ the loan recipient (borrower or borrowing firm), $b$ the bank or nonbank trustee that facilitates the loan, and $j$ the loan originator (lender or lending firm). The loan amount is thus denoted by $\mathscr{S}_{s} \cdot{ }^{11}$ Since the risky characteristic concerns borrowers only, the characteristics related to $j$ (lending firms) are not the subject of this paper and thus left to the residuals of our various regressions. As a first step, we run the following regression:

$$
\mathfrak{s}_{s}=\alpha+\alpha_{t}+\alpha_{m} \mathfrak{m}_{s}+\alpha_{r} \mathscr{I}\left(\operatorname{Risky}_{i}\right)+\varepsilon_{s},
$$

where $\mathfrak{s}$ is the interest rate spread between the loan rate and the 7 -day CHIBOR rate (measuring the degree of riskiness of each loan), $\mathfrak{m}$ is the loan maturity, $\alpha_{t}$ controls for the time fixed effect, and $\mathscr{I}\left(\operatorname{Risky}_{i}\right)$ returns 1 if the borrower is in the risky industry and 0 otherwise. The control variable vector $\alpha_{t}$ includes $g_{t-1}$ (annual change in M2 from the end of $t-2$ and the end of $t-1$ ), $\mathrm{GDP}_{t-1}$, (annual change in GDP from the end of $t-2$ and the end of $t-1$ ), and $\operatorname{Inf}_{t-1}$ (annual change in the general price level from the end of $t-2$ and

\footnotetext{
${ }^{11}$ For our transaction-based data, it is not uncommon that a borrower utilizes an entrusted loan only once for the whole sample or that a borrower utilizes two or more entrusted loans in a distant interval of many years.
} 
the end of $t-1)$. The GDP measure is real GDP measured by value added. The inflation series is the GDP deflator; we have experimented with other inflation series as in Nakamura, Steinsson, and Liu (2014) and Chang, Chen, Waggoner, and Zha (2015) but with almost identical results for all our empirical findings.

After controlling for loan maturities $\left(\alpha_{m} \mathfrak{m}_{s}\right)$, the coefficient $\alpha_{r}$ reflects the interest rate spread between risky and non-risky lending rates. ${ }^{12}$ According to the estimates reported in Table 4, additional one-year maturity reduces the lending rate spread over the 7-day CHIBOR rate by 46 basis points. After we control for maturities, the spread between risky and non-risky lending rates is $1.28 \%$ annually. The significantly estimated coefficient, $\alpha_{m}$, indicates that the longer the maturity is, the less risky entrusted lending is. This is a unique feature of Chinese entrusted loans that underlies our theoretical model's assumption that risky assets have a shorter duration than safe loans.

TABLE 4. Estimated results of regression (1)

\begin{tabular}{|c||cc|}
\hline Explanatory variable & Coefficient & (Std. Err.) \\
\hline $\mathfrak{m}_{s}: \alpha_{m}$ & $-.0384 \%^{* * *}$ & $(.0077 \%)$ \\
$\mathscr{I}\left(\right.$ Risky $\left._{i}\right): \alpha_{r}$ & $1.276 \%^{* * *}$ & $(.300 \%)$ \\
\hline Impact of a one-year longer maturity on the spread: $12 * \alpha_{m}$ & $-0.461 \%^{* * *}$ & $\mathrm{pv}=0.00$ \\
The estimate spread between risky and non-risky loan rates: $\alpha_{r}$ & $1.276 \%^{* * *}$ & $\mathrm{pv}=0.00$ \\
\hline
\end{tabular}

Note. ${ }^{*}$ represents the $10 \%$ significance level, ** the $5 \%$ significance level, and $* * *$ the $1 \%$ significance level. The abbreviation "pv" stands for p-value.

IV.2. Role of banks in entrusted lending. In this section we answer the question of whether banks played an important role in overall entrusted lending during the period of monetary tightening. To determine such a role of banks, we use the data of entrusted loans facilitated by nonbank trustees as an instrument. This instrument is necessary for us to identify banks' behavior in entrusted loans conditional on changes in monetary policy. The following regression involves double interactions between monetary policy and the type of trustees:

$$
\log \mathscr{S}_{s}=\alpha+\alpha_{t}+\alpha_{g} g_{t-1}+\beta_{b} g_{t-1} \mathscr{I}\left(\operatorname{Bank}_{b}\right)+\operatorname{Control}_{b}+\varepsilon_{s}
$$

\footnotetext{
${ }^{12}$ Except for the characteristic of whether the lending to the borrowing firm is risky, there is no need to control for borrowers' other characteristics because they do not affect the spread. As the interest rate spread, labeled by $\mathfrak{s}$, captures the degree of riskiness as well as the term premium, what should be controlled for are the maturity and other time fixed effects captured by $\alpha_{t}$.
} 
where $\mathscr{I}\left(\mathrm{Bank}_{b}\right)$ controls for the type of trustees and $\alpha_{t}$, as defined in Section IV.1, is a vector of variables controlling for aggregate time fixed effects other than the effect of monetary policy and captures, for example, business-cycle effects. The variable $\mathscr{I}\left(\operatorname{Bank}_{b}\right)$ returns 1 if the trustee is a bank and 0 otherwise. ${ }^{13}$ The additional control variable Control $_{b}$ is $\mathscr{I}\left(\mathrm{Bank}_{b}\right)$.

Following Kashyap and Stein (2000), we use the double-interaction term to capture bank's willingness to be engaged in entrusted lending. ${ }^{14}$ Table 5 reports the ordinary least squares results of regression (2) for all the coefficients (except those of control variables). The coefficient $\beta_{b}$ of the double-interaction term $g_{t-1} \mathscr{I}\left(\operatorname{Bank}_{b}\right)$ captures how much of entrusted lending is facilitated by banks in addition to the lending channeled by nonbank trustees when M2 growth changes. From the table one can see that this marginal effect is estimated to be negative and the estimate is highly significant. The negative sign means that monetary tightening (a fall in M2 growth) increases, not decreases, entrusted lending.

TABLE 5. Estimated results of regression (2)

\begin{tabular}{|c||cc|}
\hline Explanatory variable & Coefficient & (Std. Err.) \\
\hline$g_{t-1}: \alpha_{g}$ & 1.85 & $(2.77)$ \\
$g_{t-1} \mathscr{I}\left(\mathrm{Bank}_{b}\right): \beta_{b}$ & $-6.05^{* *}$ & $(2.86)$ \\
\hline Impact of money growth via NBTs: $\alpha_{g}$ & 1.85 & $\mathrm{pv}=0.51$ \\
Impact of money growth via banks: $\alpha_{g}+\beta_{b}$ & $-4.20^{* * *}$ & $\mathrm{pv}=0.00$ \\
\hline
\end{tabular}

Note. * represents the $10 \%$ significance level, ** the $5 \%$ significance level, and *** the $1 \%$ significance level. NBTs stands for nonbank trustees. The abbreviation "pv" stands for p-value.

The coefficient $\alpha_{g}$ captures the impact of monetary tightening on entrusted loans facilitated by nonbank trustees. The positive value indicates that the amount of entrusted lending facilitated nonbank trustees decreases in response to a fall in M2 growth, reflecting the impact of monetary contractions on the overall economy. Although this term is statistically insignificant, it is necessary for our difference-in-difference approach to controlling for the effect of nonbank trustees in order to capture the effect of banks. According to the estimates

\footnotetext{
${ }^{13}$ Since we do not quantify, at this point, any effect of borrowers on entrusted loans, there is no need to control for borrowers' characteristics, which are simply captured by $\varepsilon_{s}$. In Sections IV.3 and IV.5 we expand our analysis by explicitly controlling for borrowers' characteristics.

${ }^{14}$ Kashyap and Stein (2000) do not use the bank dummy as we do, but instead use the balance-sheet information to identify factors that affect banks' willingness to supply loans.
} 
in Table 5, the estimated impact of a one-percentage-point decline in M2 growth increases the amount of entrusted lending channeled by banks by $4.20 \%$ and this estimate is highly significant. This sharply estimated result indicates that banks played a different role from nonbank trustees in channeling entrusted loans in 2007-2013.

IV.3. Types of banks. Given the estimated differences between banks and nonbank trustees in channeling entrusted loans in the face of monetary policy changes, we expand the differencein-difference regression by taking into account different roles played by different types of banks as

$$
\begin{aligned}
\log \mathscr{S}_{s}=\alpha+\alpha_{t}+\alpha_{s} \mathscr{I}\left(\mathrm{Small}_{b}\right)+\alpha_{\ell} \mathscr{I}\left(\text { Large }_{b}\right)+\alpha_{g} g_{t-1} \\
\quad+\beta_{s} g_{t-1} \mathscr{I}\left(\mathrm{Small}_{b}\right)+\beta_{\ell} g_{t-1} \mathscr{I}\left(\text { Large }_{b}\right)+\text { Control }_{b}+\varepsilon_{s}
\end{aligned}
$$

where $\mathscr{I}\left(\mathrm{Small}_{b}\right)$ returns 1 if the trustee is a small bank and 0 otherwise; $\mathscr{I}\left(\right.$ Large $\left._{b}\right)$ returns 1 if the trustee is a large bank and 0 otherwise. Other control variables, denoted by $\mathrm{Control}_{b}$, are listed in Table 9.

TABLE 6. Estimated results of regression (3)

\begin{tabular}{|c||cc|}
\hline Explanatory variable & Coefficient & (Std. Err.) \\
\hline$g_{t-1}: \alpha_{g}$ & 1.92 & $(2.78)$ \\
$g_{t-1} \mathscr{I}\left(\right.$ Large $\left._{b}\right): \beta_{\ell}$ & -4.63 & $(3.10)$ \\
$g_{t-1} \mathscr{I}\left(\right.$ Small $\left._{b}\right): \beta_{s}$ & $-7.15^{* *}$ & $(2.98)$ \\
\hline Impact of money growth via NBTs: $\alpha_{g}$ & 1.92 & $\mathrm{pv}=0.48$ \\
Impact of money growth via large banks: $\alpha_{g}+\beta_{\ell}$ & -2.71 & $\mathrm{pv}=0.12$ \\
Impact of money growth via small banks: $\alpha_{g}+\beta_{s}$ & $-5.23^{* * *}$ & $\mathrm{pv}=0.00$ \\
\hline
\end{tabular}

Note. * represents the $10 \%$ significance level, ** the $5 \%$ significance level, and *** the $1 \%$ significance level. NBTs stands for nonbank trustees. The abbreviation "pv" stands for p-value.

Table 6 reports the estimated results, which are consistent with the previous results. The estimate of $\alpha_{g}$ is similar to that in Table 5. As expected, the estimated coefficients for the two double-interaction terms

$$
g_{t-1} \mathscr{I}\left(\operatorname{Large}_{b}\right) \text { and } g_{t-1} \mathscr{I}\left(\mathrm{Small}_{b}\right)
$$

sandwich the estimated double-interaction coefficient reported in Table 5 for all banks $(-4.63$ $>-6.05>-7.15)$. The statistical significance of the estimate for all banks in Table 5 comes 
from small banks as reported in Table 6. Similarly, the significant impact of monetary changes on entrusted lending via all banks stems from small banks as well. According to Table 6, a one-percentage-point fall in M2 growth has a much stronger effect on entrusted loans via small banks than those via large banks in both magnitude and significance: entrusted lending via small banks increases by $5.23 \%$ with a less than $1 \%$ significance level while entrusted lending via large banks increases by only $2.71 \%$, which is statistically insignificant. M2 growth also has an insignificant impact on entrusted lending facilitated by nonbank trustees. When monetary policy contracts, therefore, small banks' behavior differs quantitatively from nonbank trustees as well as large banks. This evidence is consistent with evidence of why large banks differ from small banks on their balance-sheet behavior as provided in Section V.

IV.4. Types of loans. In the preceding analysis we use the data on nonbank trustees as an instrument to effectively identify banks' willingness to facilitate entrusted loans. In this section we use the data on entrusted lending to the risky industry as another instrument to identify banks' risk-taking behavior, which involve triple interactions in the following regression.

$$
\begin{array}{r}
\log \mathscr{S}_{s}=\alpha+\alpha_{t}+\alpha_{s e c}+\alpha_{g} g_{t-1}+\beta_{b} g_{t-1} \mathscr{I}\left(\operatorname{Bank}_{b}\right)+\gamma_{n} g_{t-1} \mathscr{I}\left(\operatorname{Risky}_{i}\right) \\
+\gamma_{b} g_{t-1} \mathscr{I}\left(\operatorname{Bank}_{b}\right) \mathscr{I}\left(\operatorname{Risky}_{i}\right)+\operatorname{Control}_{i b}+\varepsilon_{s}
\end{array}
$$

where $\mathscr{I}\left(\operatorname{Risky}_{i}\right)$ returns 1 if the borrower is in the risky industry and 0 otherwise, $\alpha_{\text {sec }}$ controls for borrowers' characteristics at the industry level, and additional control variables, denoted by Control $_{i b}$, are listed in Table 9 . Because the risky character is identified at the industry level according to the 2010 announcement issued by the Ministry of Industry and Information Technology, we need to control for other borrower characteristics at the industry level such as the size, market power (monopoly), capital intensity (labor share), and share of state-owned enterprises (SOEs) in each industry. The control variable $\alpha_{\text {sec }}$ has 46 dummies representing 46 classified industries.

Why do we use the industry risk represented by $\mathscr{I}\left(\right.$ Risky $\left._{i}\right)$, not firm-specific risks, as an instrument to identify the riskiness of entrusted lending? Firm-specific risks can be diversified by banks, but the industry-level risk is non-diversifiable and it is this kind of risk that Chinese policymakers care about and view as a serious threat to the banking system. A series of laws and regulations aim at curtailing the industry-level risk, which is specifically defined by the law. 
With the data on risky entrusted lending as an instrument, the triple-interaction term plays a crucial role in isolating the effect of banks' penchant for channeling risky loans when monetary policy changes. If the triple-interaction term

$$
g_{t-1} \mathscr{I}\left(\operatorname{Bank}_{b}\right) \mathscr{I}\left(\operatorname{Risky}_{i}\right)
$$

were left out of regression (4), the double-interaction term $g_{t-1} \mathscr{I}\left(\mathrm{Risky}_{i}\right)$ would capture the effect of monetary policy changes on risky entrusted borrowing no matter who is the trustee. After this double-interaction term is controlled for, the above triple-interaction term helps isolate the effect of monetary tightening on banks' willingness to channel risky entrusted lending. ${ }^{15}$ Table 7 reports the results consistent with the findings reported in Tables 5 and 6.

TABLE 7. Estimated results of regression (4)

\begin{tabular}{|c|cc|}
\hline Explanatory variable & Coefficient & (Std. Err.) \\
\hline$g_{t-1}: \alpha_{g}$ & $-5.52^{*}$ & $(2.88)$ \\
$g_{t-1} \mathscr{I}\left(\mathrm{Risky}_{i}\right): \gamma_{n}$ & $5.66^{* *}$ & $(2.42)$ \\
$g_{t-1} \mathscr{I}\left(\mathrm{Bank}_{b}\right): \beta_{b}$ & 2.95 & $(2.68)$ \\
$g_{t-1} \mathscr{I}\left(\mathrm{Bank}_{b}\right) \mathscr{I}\left(\mathrm{Risky}_{i}\right): \gamma_{b}$ & $-4.01^{* *}$ & $(1.67)$ \\
\hline Impact of money growth on risky loans via NBTs: $\alpha_{g}+\gamma_{n}$ & 0.14 & $\mathrm{pv}=0.96$ \\
Impact of money growth on risky loans via banks: $\alpha_{g}+\beta_{b}+\gamma_{b}$ & $-6.58^{* * *}$ & $\mathrm{pv}=0.00$ \\
\hline
\end{tabular}

Note. ${ }^{*}$ represents the $10 \%$ significance level, $* *$ the $5 \%$ significance level, and $* * *$ the $1 \%$ significance level. NBTs stands for nonbank trustees. The abbreviation "pv" stands for p-value.

The estimate of $\alpha_{g}$ indicates that a one-percentage-point fall in M2 growth increases non-risky entrusted lending by nonbank trustees by $5.52 \%$ with only the $10 \%$ significance level. With the presence of triple interactions, the sum of $\alpha_{g}$ and the double-interaction term $g_{t-1} \mathscr{I}\left(\operatorname{Risky}_{i}\right)$ measures the impact of monetary policy changes on risky entrusted lending channeled by nonbank trustees, which is estimated to be insignificant. By contrast, the impact of monetary policy changes on risky entrusted lending channeled by banks is estimated to be very strong in both magnitude and significance; the estimate indicates that a one-percentage-point decline in M2 growth leads to a $6.58 \%$ increase of risky entrusted lending with a less than $1 \%$ significance level. The instrument of the data on risky entrusted

\footnotetext{
${ }^{15}$ See a similar methodology of Jiménez, Ongena, Peydró, and Saurina (2014) in identifying banks' risktaking behavior.
} 
loans helps identify the difference between banks and nonbank trustees in facilitating risky entrusted loans and determine the magnitude and significance of risky loans channeled by banks in response to monetary contractions.

IV.5. Types of loans interacting with types of banks. Since the share of the amount of risky entrusted lending facilitated by nonbank trustees in total risky entrusted loans was only $23.3 \%$ during our sample period of 2007-2013, it is not surprising that the impact of monetary policy changes on these loans is estimated to be insignificant. The remaining share was channeled by commercial banks; among them, small banks funneled risky entrusted lending as much as large banks did (37.2\% vs. 39.5\%). Now that Section IV.4 establishes evidence that banks were principally responsible for channeling more risky entrusted loans when money growth slowed, a natural question is whether small banks behave differently from large banks as we find in Section IV.3. To answer this question, we expand the tripleinteraction regression (4) by separating large and small banks as follows:

$$
\begin{array}{r}
\log \mathscr{S}_{s}=\alpha+\alpha_{t}+\alpha_{s e c}+\alpha_{g} g_{t-1}+\beta_{s} g_{t-1} \mathscr{I}\left(\mathrm{Small}_{b}\right)+\beta_{\ell} g_{t-1} \mathscr{I}\left(\operatorname{Large}_{b}\right) \\
+\gamma_{n} g_{t-1} \mathscr{I}\left(\operatorname{Risky}_{i}\right)+\gamma_{s} g_{t-1} \mathscr{I}\left(\mathrm{Small}_{b}\right) \mathscr{I}\left(\mathrm{Risky}_{i}\right)+\gamma_{\ell} g_{t-1} \mathscr{I}\left(\operatorname{Large}_{b}\right) \mathscr{I}\left(\mathrm{Risky}_{i}\right) \\
+\operatorname{Control}_{i b}+\varepsilon_{s}
\end{array}
$$

where additional control variables Control $_{i b}$ are listed in Table 9. Regression (5) allows the interactions between types of loans and types of banks and is thus our benchmark regression for this paper.

The estimated results for nonbank trustees, as reported in Table 8, remain the same. That is, nonbank trustees tend to facilitate non-risky, rather than risky, entrusted lending during the period of monetary slowdown. Although risky entrusted lending channeled by both large and small banks increases in response to monetary contractions, small banks tend to do more than large banks in both magnitude and significance. According to the estimates reported in Table 8, a one-percentage-point drop in M2 growth has the impact of a $7.57 \%$ increase in risky entrusted lending funneled by small banks and the significance level of the estimate is $0.002 \%$, while risky entrusted lending channeled by large banks is estimated to increase by $5.28 \%$ increase with the $3 \%$ significance level. The significantly estimated impact for banks as a whole, reported in Table 7 , is between these two estimates $(-5.28>-6.58>-7.57)$. Consistent with the results reported in Table 6 , the effect on risky lending via small banks is stronger than that via large banks in both magnitude and significance. 
TABLE 8. Estimated results of regression (5)

\begin{tabular}{|c||cc|}
\hline Explanatory variable & Coefficient & (Std. Err.) \\
\hline$g_{t-1}: \alpha_{g}$ & $-5.21^{*}$ & $(2.87)$ \\
$g_{t-1} \mathscr{I}\left(\right.$ Risky $\left._{i}\right): \gamma_{n}$ & $5.25^{* *}$ & $(2.39)$ \\
$g_{t-1} \mathscr{I}\left(\right.$ Large $\left._{b}\right): \beta_{\ell}$ & 2.63 & $(2.85)$ \\
$g_{t-1} \mathscr{I}\left(\right.$ Small $\left._{b}\right): \beta_{s}$ & 2.66 & $(2.82)$ \\
$g_{t-1} \mathscr{I}\left(\operatorname{Larg}_{b}\right) \mathscr{I}\left(\right.$ Risky $\left._{i}\right): \gamma_{\ell}$ & $-2.70^{*}$ & $(1.69)$ \\
$g_{t-1} \mathscr{I}\left(\right.$ Small $\left._{b}\right) \mathscr{I}\left(\right.$ Risky $\left._{i}\right): \gamma_{s}$ & $-5.02^{* * *}$ & $(1.81)$ \\
\hline Impact of money growth on risky loans via NBTs: $\alpha_{g}+\gamma_{n}$ & 0.04 & $\mathrm{pv}=0.99$ \\
Impact of money growth on risky loans via large banks: $\alpha_{g}+\beta_{\ell}+\gamma_{\ell}$ & $-5.28^{* *}$ & $\mathrm{pv}=0.03$ \\
Impact of money growth on risky loans via small banks: $\alpha_{g}+\beta_{s}+\gamma_{s}$ & $-7.57^{* * *}$ & $\mathrm{pv}=0.00$ \\
\hline
\end{tabular}

Note. $*$ represents the $10 \%$ significance level, ${ }^{* *}$ the $5 \%$ significance level, and ${ }^{* * *}$ the $1 \%$ significance level. NBTs stands for nonbank trustees. The abbreviation "pv" stands for p-value.

TABLE 9. Relevant effects to be controlled

\begin{tabular}{|c|c|c|c|c|c|c|c|}
\hline \multirow[t]{2}{*}{ Control variable } & \multicolumn{7}{|c|}{ Regression } \\
\hline & $(2)$ & $(3)$ & $(4)$ & $(5)$ & (6) & (7) & $(8)$ \\
\hline $\mathrm{GDP}_{t-1}:$ macroeconomic effect & $\mathrm{X}$ & $\mathrm{X}$ & $\mathrm{X}$ & $\mathrm{X}$ & $\mathrm{X}$ & $\mathrm{X}$ & $\mathrm{X}$ \\
\hline $\mathrm{Inf}_{t-1}:$ macroeconomic effect & $\mathrm{X}$ & $\mathrm{X}$ & $\mathrm{X}$ & $\mathrm{X}$ & $\mathrm{X}$ & $\mathrm{X}$ & $\mathrm{X}$ \\
\hline $\mathscr{I}\left(\mathrm{Bank}_{b}\right):$ trustee type & $\mathrm{X}$ & & $\mathrm{X}$ & & & & \\
\hline $\mathscr{I}\left(\right.$ Large $\left._{b}\right)$ : trustee type & & $\mathrm{X}$ & & $\mathrm{X}$ & & & $\mathrm{X}$ \\
\hline $\mathscr{I}\left(\mathrm{Small}_{b}\right):$ trustee type & & $\mathrm{X}$ & & $\mathrm{X}$ & & $\mathrm{X}$ & $\mathrm{X}$ \\
\hline $\mathscr{I}\left(\right.$ Risky $\left._{i}\right)$ : borrower type & & & $\mathrm{X}$ & $\mathrm{X}$ & $\mathrm{X}$ & $\mathrm{X}$ & $\mathrm{X}$ \\
\hline$\alpha_{s e c}:$ industry fixed effect & & & $\mathrm{X}$ & $\mathrm{X}$ & $\mathrm{X}$ & $\mathrm{X}$ & $\mathrm{X}$ \\
\hline $\mathscr{I}\left(\operatorname{Risky}_{i}\right) \mathscr{I}\left(\right.$ Bank $\left._{b}\right)$ : double interactions & & & $\mathrm{X}$ & & & & \\
\hline $\mathscr{I}\left(\right.$ Risky $\left._{i}\right) \mathscr{I}\left(\right.$ Large $\left._{b}\right)$ : double interactions & & & & $\mathrm{X}$ & & & $\mathrm{X}$ \\
\hline $\mathscr{I}\left(\right.$ Risky $\left._{i}\right) \mathscr{I}\left(\right.$ Small $\left._{b}\right)$ : double interactions & & & & $\mathrm{X}$ & & $\mathrm{X}$ & $\mathrm{X}$ \\
\hline
\end{tabular}

Note. "X" indicates that the corresponding fixed effect is included. Regression (5) is the benchmark regression.

IV.6. Further robustness analysis. In the preceding sections we show that the data on entrusted lending facilitated by nonbank trustees serve as a powerful instrument to help 
identify banks' behavior. It is therefore necessary to provide a careful analysis of the quantitative importance of this instrument. A nonbank trustee is an ideal trustee as it is the kind of trustee as intended by the law (i.e., the PBC's 2000 guidelines on entrusted lending). Nonbank trustees face no deposit withdrawal risks and bear no credit risks as commercial banks do. Consequently, the banking regulations we have discussed thus far do not apply to these trustees. In this sense nonbank trustees act truly as middlemen. Entrusted loans facilitated by nonbank trustees capture demand from borrowers and supply from lenders. Controlling for these data with the difference-in-difference approach, therefore, enables us to identify banks' willingness to engage in entrusted lending.

A natural question is what the estimated results would indicate if we exclude from the sample the transactions facilitated by nonbank trustees. With this exclusion, the effective sample size is reduced to 650 and the triple-interaction regression represented by (4) is reduced to the following double-interaction regression:

$$
\log \mathscr{S}_{s}=\alpha+\alpha_{t}+\alpha_{s e c}+\alpha_{g} g_{t-1}+\gamma_{r} g_{t-1} \mathscr{I}\left(\operatorname{Risky}_{i}\right)+\operatorname{Control}_{i}+\varepsilon_{s}
$$

where an additional control variable Control $_{i}$ is listed in Table 9. The estimated results are reported in Table 10.

TABLE 10. Estimated results of regression (6)

\begin{tabular}{|c||cc|}
\hline Explanatory variable & Coefficient & (Std. Err.) \\
\hline$g_{t-1}: \alpha_{g}$ & -2.31 & $(1.56)$ \\
$g_{t-1} \mathscr{I}\left(\right.$ Risky $\left._{i}\right): \gamma_{r}$ & 0.93 & $(2.01)$ \\
\hline Impact of money growth on non-risky loans via banks: $\alpha_{g}$ & -2.31 & $\mathrm{pv}=0.14$ \\
Impact of money growth on risky loans via banks: $\alpha_{g}+\gamma_{r}$ & -1.38 & $\mathrm{pv}=0.41$ \\
\hline
\end{tabular}

Note. ${ }^{*}$ represents the $10 \%$ significance level, ** the $5 \%$ significance level, and ${ }^{* * *}$ the $1 \%$ significance level. NBTs stands for nonbank trustees. The abbreviation "pv" stands for p-value.

As one can see from Table 10, all the estimates of the impact of monetary policy changes on entrusted loans channeled by banks, risky or not, have a small magnitude and are statistically insignificant. The absence of the nonbank-trustee instrument creates uninformative results. Without the nonbank-trustee instrument, one may still use the loans channeled by large banks as an instrument to identify small banks' risk-taking behavior as in the following regression similar to the triple-interaction benchmark regression (5) but without the data on 
entrusted loans facilitated by nonbank trustees:

$$
\begin{aligned}
\log \mathscr{S}_{s}=\alpha+\alpha_{t}+\alpha_{s e c}+\alpha_{g} g_{t-1}+\beta_{s} g_{t-1} \mathscr{I}\left(\mathrm{Small}_{b}\right)+\gamma_{\ell} g_{t-1} \mathscr{I}\left(\mathrm{Risky}_{i}\right) \\
+\gamma_{s} g_{t-1} \mathscr{I}\left(\mathrm{Small}_{b}\right) \mathscr{I}\left(\mathrm{Risky}_{i}\right)+\mathrm{Control}_{i b}+\varepsilon_{s}
\end{aligned}
$$

where additional control variables $\mathrm{Control}_{i b}$ are listed in Table 9. The estimated results are reported in Table 7.

TABLE 11. Estimated results of regression (7)

\begin{tabular}{|c||cc|}
\hline Explanatory variable & Coefficient & (Std. Err.) \\
\hline$g_{t-1}: \alpha_{g}$ & -1.93 & $(1.98)$ \\
$g_{t-1} \mathscr{I}\left(\mathrm{Risky}_{i}\right): \gamma_{\ell}$ & 1.70 & $(2.08)$ \\
$g_{t-1} \mathscr{I}\left(\mathrm{Small}_{b}\right): \beta_{s}$ & -0.59 & $(1.93)$ \\
$g_{t-1} \mathscr{I}\left(\mathrm{Small}_{b}\right) \mathscr{I}\left(\right.$ Risky $\left._{i}\right): \gamma_{s}$ & $-2.22^{* *}$ & $(1.08)$ \\
\hline Impact of money growth on non-risky loans via large banks: $\alpha_{g}$ & -1.93 & $\mathrm{pv}=0.33$ \\
Impact of money growth on risky loans via large banks: $\alpha_{g}+\gamma_{\ell}$ & -0.23 & $\mathrm{pv}=0.91$ \\
Impact of money growth on risky loans via small banks: $\alpha_{g}+\beta_{s}+\gamma_{s}$ & $-4.74^{* *}$ & $\mathrm{pv}=0.02$ \\
\hline
\end{tabular}

Note. ${ }^{*}$ represents the $10 \%$ significance level, ** the $5 \%$ significance level, and *** the $1 \%$ significance level. The abbreviation "pv" stands for p-value.

One can see from Table 7 that the large-bank instrument helps identify the risk-taking behavior of small banks. Indeed, the impact of monetary policy changes on risky entrusted loans funneled by small banks is estimated to be $-4.74 \%$ with the $5 \%$ significance level. But both magnitude and significance are considerably underestimated when compared to the results in Table 8. Moreover, since the lack of the nonbank-trustee instrument makes it difficult, if not impossible, to identify large banks' behavior, the estimate of the impact of monetary policy changes on risky entrusted loans channeled by large banks has a minute value $(-0.23)$ without any statistical significance. These analyses demonstrate the practical and quantitative importance of using the data of entrusted loans facilitated by nonbank trustees as an instrument to identify the behavior of banks, large or small.

One of the most important transmission features of China's monetary policy is the unequivocal effect of M2 supply on bank loans and thus on bank deposits. As shown in Figure 1, M2 growth and deposit growth move in tandem. By changing monetary policy through control of M2 growth, the government effectively controlled growth of the banking system at least prior to 2014. Indeed, the correlation between M2 and deposit growth rates is as high 
as 0.93 during the period of 2007-2013 and 0.96 during the period of 2010-2013. When deposit growth slows down, banks' activities on balance sheet, such as growth in traditional bank loans, would slow down accordingly. Banks would have an incentive to engage in offbalance-sheet activities. To see whether our results hold for bank deposits in place of M2, we run the following triple-interaction regression equivalent to the benchmark regression (5) except that M2 growth is now replaced by deposit growth:

$$
\begin{array}{r}
\log \mathscr{S}_{s}=\alpha+\alpha_{t}+\alpha_{s e c}+\alpha_{d} d_{t-1}+\beta_{s} d_{t-1} \mathscr{I}\left(\operatorname{Small}_{b}\right)+\beta_{\ell} d_{t-1} \mathscr{I}\left(\operatorname{Large}_{b}\right) \\
+\gamma_{n} d_{t-1} \mathscr{I}\left(\operatorname{Risky}_{i}\right)+\gamma_{s} d_{t-1} \mathscr{I}\left(\operatorname{Small}_{b}\right) \mathscr{I}\left(\operatorname{Risky}_{i}\right)+\gamma_{\ell} d_{t-1} \mathscr{I}\left(\operatorname{Large}_{b}\right) \mathscr{I}\left(\operatorname{Risky}_{i}\right) \\
+\operatorname{Control}_{i b}+\varepsilon_{s}
\end{array}
$$

where $d_{t-1}$ represents the growth rate of deposits at $t-1$ (annual change from the end of $t-2$ to the end of $t-1$ ) and additional control variables, denoted by Control $_{i b}$, are listed in Table 9 .

TABLE 12. Estimated results of regression (8)

\begin{tabular}{|c||cc|}
\hline Explanatory variable & Coefficient & (Std. Err.) \\
\hline$d_{t-1}: \alpha_{d}$ & $-5.31^{*}$ & $(2.71)$ \\
$d_{t-1} \mathscr{I}\left(\right.$ Risky $\left._{i}\right): \gamma_{n}$ & $5.08^{* *}$ & $(2.27)$ \\
$d_{t-1} \mathscr{I}\left(\right.$ Large $\left._{b}\right): \beta_{\ell}$ & 2.80 & $(2.67)$ \\
$d_{t-1} \mathscr{I}\left(\right.$ Small $\left._{b}\right): \beta_{s}$ & 2.73 & $(2.65)$ \\
$d_{t-1} \mathscr{I}\left(\right.$ Large $\left._{b}\right) \mathscr{I}\left(\right.$ Risky $\left._{i}\right): \gamma_{\ell}$ & $-2.74^{*}$ & $(1.68)$ \\
$d_{t-1} \mathscr{I}\left(\right.$ Small $\left._{b}\right) \mathscr{I}\left(\right.$ Risky $\left._{i}\right): \gamma_{s}$ & $-5.01^{* * *}$ & $(1.79)$ \\
\hline Impact of deposit growth on risky loans via NBTs: $\alpha_{d}+\gamma_{n}$ & -0.23 & pv=0.92 \\
Impact of deposit growth on risky loans via large banks: $\alpha_{d}+\beta_{\ell}+\gamma_{\ell}$ & $-5.25^{* *}$ & pv=0.03 \\
Impact of deposit growth on risky loans via small banks: $\alpha_{d}+\beta_{s}+\gamma_{s}$ & $-7.59^{* * *}$ & pv=0.00 \\
\hline
\end{tabular}

Note. $*$ represents the $10 \%$ significance level, ** the $5 \%$ significance level, and *** the $1 \%$ significance level. NBTs stands for nonbank trustees. The abbreviation "pv" stands for p-value.

The estimated results in Table 12 are very similar to those in Table 8 . These robust findings, reflecting the close relationship between M2 growth and deposit growth in China, continue to show the difference between large and small banks in channeling risky entrusted loans. Such a behavioral difference, as discussed in Section V, is not due to the size difference between large and small banks in their assets or equities, but stems from institutional 
asymmetry in several important aspects. First, large banks enjoy implicit government guarantees on their bank loans. Second, large banks, being state-owned, are a primary funding source for non-financial SOEs and other large firms of strategic importance to the government. Third, as a result, large banks have a stable and broad customer relationship with both households and firms so that they encounter little difficulty in acquiring additional deposits to weather unexpected deposit shortfalls. These advantages are hardly enjoyed by small banks. Such institutional asymmetry gives small banks, not large banks, a strong incentive to bring their risk-taking behavior off balance sheet as found in this section into their balance-sheet activity. In Section $\mathrm{V}$ we provide the relevant institutional background as well as further evidence that small banks were prone to bring the risk off balance sheet into the balance sheet in the form of nonloan investment while there is no such evidence for large banks. In Section VI we build a theory for a coherent explanation of such risk-taking behavior of small banks in the context of China's unique institutional background.

\section{Institutional ASYMMETRY}

In this section we provide a narrative of China's institutional background and discuss the unique features of China's banking system that are pertinent to our paper.

V.1. The usual suspects. Obvious candidates for explaining the difference in risk-taking behavior between large and small banks relate to balance sheet information that reveals how banks respond to monetary and regulatory policies. The monetary and regulatory authorities in China had in place three major regulations on all commercial banks during 2007-2013: capital requirement, reserve requirement, and LDR requirement. We provide evidence on whether there was a notable difference between large and small banks in meeting each of the three requirements.

First, both large and small banks met the capital requirement by a comfortable margin as shown in Table 13. One can see from the table that the difference in capital adequacy ratios between large and small banks was inconsequential and that both their capital ratios were far above the capital requirement ratio of $8 \%$.

Second, small banks had a considerably higher excess reserve ratio than large banks. The numbers reported in Table 13 are not available in any electronic data format. We read the annual report of each commercial bank in a pdf file downloaded from WIND (each pdf file has over-100 pages) and find the numbers for excess reserves and total deposits in the chapter called "Notes of Financial Statement." We compute the excess reserve ratio for each bank 
TABLE 13. Capital adequacy ratios, excess reserve ratios, and LDRs across types of banks and samples

\begin{tabular}{c|cccccccc}
\hline \multirow{2}{*}{ Description } & \multicolumn{2}{|c}{ Capital adequacy ratio } & & \multicolumn{2}{c}{ Excess reserve ratio } & & \multicolumn{2}{c}{ Loan-to-deport ratio } \\
\cline { 2 - 3 } & $2007-2013$ & $2010-2013$ & & $2007-2013$ & $2010-2013$ & & $2007-2013$ & $2010-2013$ \\
\hline Large banks & $12.60 \%$ & $12.87 \%$ & & $1.95 \%$ & $1.60 \%$ & & $64.03 \%$ & $66.22 \%$ \\
Small banks & $11.88 \%$ & $12.30 \%$ & & $4.47 \%$ & $3.17 \%$ & & $70.82 \%$ & $67.89 \%$ \\
Overall & $12.35 \%$ & $12.65 \%$ & & $2.51 \%$ & $2.01 \%$ & & $66.22 \%$ & $66.80 \%$ \\
\hline
\end{tabular}

Note. Each reported ratio is weighted by bank assets. The calculation is based on the balance-sheet information of all commercial banks reported by Bankscope and WIND. Capital adequacy ratios and LDRs are from Bankscope and excess reserve ratios are from WIND.

in every year, take a weighted average of these ratios for all the banks within the group (the large or small type) in each year, and then average these ratios across years. As clearly shown in Table 13, small banks, like large banks, had no problem managing their reserves and the reported excess reserve ratios indicate that small banks had more cushion than large banks in meeting the reserve requirement.

Third, both large and small banks met the LDR requirement of $75 \%$ and the difference in LDR between large and small banks became smaller over time. ${ }^{16}$ For the period of monetary tightening (2010-2013), the difference almost did not exist. The issue for banks is not the LDR ceiling per se, but rather the risk of hitting the ceiling due to unexpected deposit shortfalls. Such a risk is an important ingredient in our theory developed in Section VI.

In summary, all banks large or small met the three major policy requirements and in this respect there is no difference between large and small banks. It is therefore not these policies per se that helped explain the robust empirical findings of how small banks behaved differently from large banks in channeling entrusted loans. The aforementioned obvious balance-sheet candidates are unlikely to be a major explanation of asymmetric responses of small and large banks to monetary policy changes in their risk-taking behavior. A less obvious candidate for explanation is banks' ability to cope with the pressures of deposit shortfalls,

\footnotetext{
${ }^{16}$ Since only the PBC (not central banks in many other countries) requires a bank to report the LDR and since Bankscope collects variables that are common across countries, a direct measure of the LDR is not provided by Bankscope. We construct this measure as the ratio of "gross loans" to "total customer deposits." For a listed bank, we verify this measure with the reported LDR published by the bank's annual report and they match. The published ratio must comply with the PBC's requirement by law.
} 
which has been an intensive topic within the Chinese policy circle. This is a unique feature of China's banking system and has yet to be thoroughly analyzed by researchers. As discussed in the following sections, it is this institutional detail that helps explain the difference in risk-taking behavior between large and small banks.

\section{V.2. Banking regulations against the macroeconomic background. Bank loans in} China are a major source of financing to fund economic activities; changes in bank loans are largely influenced by monetary policy. As shown in Figure 1, the growth rates of M2 and total bank loans moved in tandem, reflecting the unique characteristic of China's monetary policy of controlling bank lending by adjusting growth of monetary aggregates.

In response to the 2008 global financial crisis, the Chinese government injected money supply into the banking system in late 2008 and early 2009 in which growth in M2 growth doubled and so did growth in bank loans. For fears of rising inflation, the PBC began to tighten money supply and bank lending toward the end of 2009. As a result of monetary tightening, growth in bank loans and deposits fell steadily since 2009. To counter the rapid slowdown in bank loans, shadow banking activities sprang up (Figure 2). Entrusted lending in particular has become the second largest financing source of loans after traditional bank lending. The volume of newly originated entrusted loans reached its climax in 2013. In that year, total shadow lending was equivalent to nearly $34 \%$ of total social financing excluding stocks and bonds, and the amount of entrusted lending accounted for nearly $49 \%$ of total shadow lending. ${ }^{17}$

Both monetary tightening and a series of regulatory changes contributed to the rapid rise of China's shadow banking and to the observed opposite movements in bank loans and entrusted loans. Loans between nonfinancial firms, which define the concept of entrusted lending, were practiced in China at the outset of advanced economic reforms in the early 1990s but did not really blossom until after 2009. In 1996 the PBC issued "General Rules for Loans" that allowed entrusted lending. In 2000 the PBC provided formal operational guidelines for commercial banks to be trustees of entrusted loans in its May (No. 100) "Notice on Issues Related to Practices of Commercial Banks in Entrusted Lending." The key requirement in these guidelines was the mandatory participation of financial institutions acting as a trustee to facilitate loan transactions between the two nonfinancial firms. This regulation required the participating financial institution to verify that all the paperwork

\footnotetext{
${ }^{17}$ Total shadow lending is the sum of entrusted loans, trusted loans, and bank acceptances.
} 
met various legal forms and requirements and encouraged financial institutions to use their specialty in monitoring and screening technology to help curtail nonperforming or risky loans.

As found by our empirical analysis in Section IV, although entrusted loans facilitated by nonbank trustees tended to be safe, those channeled by banks ended up in the real estate and overcapacity industries. The incentive for banks to engage in funneling risky loans stemmed from a series of regulatory changes and restrictions imposed on banks. In 2006 the State Council, concerned with China's real-estate and overcapacity industry, issued a notice to accelerate the restructuring process of the risky industry. The CBRC took concrete steps in 2010 to curtail expansion of traditional credits from the banking sector to the risky industry. Subsequently, in 2013 the State Council issued an order that strictly prohibited banks from providing new credits to the risky industry.

On top of these regulations, the PBC imposed an additional restriction on traditional loans made by banks. In as early as 1994 the PBC established a $75 \%$ ceiling on the ratio of traditional loans to total bank deposits for the entire banking system for the purpose of curbing risk-taking behavior and reducing the potential systemic risk. This ceiling was not credibly enforced until the late 2000s. In 2011, through the CARPAL system (the Chinese version of Basel III), the PBC began to monitor the LDR during the course of the year (quarterly) rather than at the end of the year.

V.3. The last-minute rush for deposits by small banks. As M2 growth began to slow down in late 2009, the pressure of unexpected deposit shortfalls against the LDR ceiling began to build up, that is, banks were more vulnerable to deposit withdrawal risks. ${ }^{18}$ While the LDR regulation applied to all banks, small banks had disadvantages in attracting additional deposits to meet shortfalls, especially around the time when the LDR was closely monitored by the $\mathrm{PBC}$ at the end of the quarter. In fact, the government uses the phrase "the last-minute rush (chongshidian in Chinese)" to refer to the last-minute actions taken by banks to pay high prices to artificially increase temporary deposits in order to recoup deposit shortfalls when the monitoring time is near. ${ }^{19}$

In practice, the last-minute rush was more relevant to small banks than large banks. Stateowned large banks, with branches in almost every corner of the country and with implicit

\footnotetext{
${ }^{18}$ For detailed discussions of such risks, see the PBC's various "Financial Stability Reports" published in the early 2010s.

${ }^{19}$ See the proclamation "Number 236 Notice on Strengthening Commercial Banks Deposit Stability Management" jointly announced on 12 September 2014 by the CBRC, the Ministry of Finance, and the PBC.
} 
guarantees from the central government, had advantages of attracting household deposits on a broad basis at low costs. Moreover, because nonfinancial SOEs as well as nonfinancial large non-SOE firms had easy and preferential access to loans made by the large banks (Chang, Chen, Waggoner, and Zha, 2015), these firms in return were willing to place additional deposits in large banks when requested by these banks. The large banks' long-standing customer relationships with a broad base of firms and households enabled them to weather deposit shortages without much cost.

These advantages were hardly enjoyed by small banks, which often had relationships with only local and small firms and whose customer base for deposits was not nearly as broad and stable. As a result, when the deposit monitoring time came near, small banks had to resort to higher prices for additional deposits by either manipulating the timing of expirations of the WMP products or offering a much higher deposit rate than the legal ceiling imposed by the PBC. The twin problem of deposit shortfalls and high costs for small banks to attract deposits, as well as other related issues, has been discussed extensively in various Chinese financial newspapers and some Chinese academic articles (Ba, Yan, and Wang, 2013, for example).

V.4. The asset side of banks' balance sheet. As shown in the bottom panel of Figure 2, the share of entrusted loans in the sum of entrusted lending and bank lending tripled during the monetary tightening period. According to our micro data, more than $60 \%$ of the total amount of entrusted loans was channeled to the risky industry between 2007 and 2013; out of these risky entrusted loans, $77 \%$ was facilitated by commercial banks. How such risky entrusted lending was connected with the asset side of the bank's balance sheet is a focus of this section.

As early as 28 May 2010, the PBC and CBRC issued a joint new regulation, called "Notice on Financial Services to Further Support Energy Saving and Eliminate Backward-Production Capacity," to ensure "the soundness of the banking system." The main purpose of this new regulation was to reinforce the earlier laws of prohibiting banks from originating new bank loans to the risky industry. While this and earlier laws made traditional bank loans safe, they created their own unforeseen problem. Because small banks faced much higher costs than large banks, implicit or explicit, in attracting deposits to cope with the LDR regulation risk, small banks had an incentive to reduce bank loans that were subject to the LDR regulation and increase nonloan investment that was not subject to the same regulation. 
The LDR regulation risk is a unique institutional characteristic of China because the LDR ceiling is set arbitrarily by the PBC. On the asset side of banks' balance sheet, there is one major entry called "account-receivable investment (ARI)," which is an asset not counted as part of bank loans. As our theory in Section VI predicts, this nonloan investment can become an effective device for small banks to circumvent both regulations simultaneously: the LDR ceiling and the safe-loan law. But how was ARI on banks' balance sheet related to entrusted loans off balance sheet? When small banks were engaged in risky entrusted lending during the period of 2007-2013, they purchased the beneficiary rights of those loans (entrusted rights), which were recorded in the category of ARI. This nonloan investment category, even though on the asset side of bank's balance sheet, was nonetheless immune from both LDR and safe-loan regulations and thus gave small banks an incentive to funnel risky entrusted loans by either purchasing entrusted rights or offering implicit guarantees to such loans.

TABLE 14. Correlation between new entrusted loans $(\mathscr{L})$ channeled by banks and changes in ARI for two different samples.

\begin{tabular}{c||ccccc}
\hline \multirow{2}{*}{ Description } & \multicolumn{2}{|c}{ 2007-2013 Sample } & & \multicolumn{2}{c}{ 2010-2013 Sample } \\
\cline { 2 - 3 } \cline { 5 - 6 } & Small banks & Large banks & & Small banks & Large banks \\
\hline Corr $(\Delta \mathrm{ARI}, \mathscr{L})$ & $.467^{* * *}(.001)$ & $-.092(.617)$ & & $.495^{* * *}(.007)$ & $.025(.929)$ \\
$\operatorname{Corr}\left(\Delta \frac{\mathrm{ARI}}{\mathrm{ARI}+B}, \mathscr{L}\right)$ & $.386^{* * *}(.010)$ & $-.121(.509)$ & & $.330^{*}(.087)$ & $.008(.978)$ \\
\hline
\end{tabular}

Note. The symbol "B" stands for traditional bank loans. The numbers in parentheses represent p-values.

Chinese small banks had a penchant for partaking in risky loan activities because their expected returns were higher than those on non-risky loans (see Table 19 in Section VI.5); as we find in our own empirical study, they were indeed engaged in funneling risky entrusted loans during the period of monetary tightening, more so than large banks. The sharp contrast of small banks to large banks in their risk-taking behavior is manifested by the findings presented in Table 14, which reports the correlations of entrusted loans channeled by banks off balance sheet and nonloan investment on balance sheet. For both samples of 20072013 and 2010-2013, the correlation between new entrusted loans and changes in ARI is significantly positive for small banks, while the same correlation is statistically insignificant for large banks. This result holds for changes in $\frac{\mathrm{ARI}}{\mathrm{ARI}+B}$. For large banks, the same correlations are either close to zero or negative without statistical significance. 
TABLE 15. Correlation between new risky entrusted loans $\left(\mathscr{L}^{r}\right)$ channeled by banks and changes in ARI for two different samples.

\begin{tabular}{c||ccccc}
\hline \multirow{2}{*}{ Description } & \multicolumn{2}{|c}{ 2007-2013 Sample } & & \multicolumn{2}{c}{ 2010-2013 Sample } \\
\cline { 2 - 3 } \cline { 6 - 7 } & Small banks & Large banks & & Small banks & Large banks \\
\hline Corr $\left(\Delta \mathrm{ARI}, \mathscr{L}^{r}\right)$ & $.433^{* * *}(.003)$ & $-.058(.754)$ & & $.501^{* * *}(.002)$ & $.176(.459)$ \\
$\operatorname{Corr}\left(\Delta \frac{\mathrm{ARI}}{\mathrm{ARI}+B}, \mathscr{L}^{r}\right)$ & $.367^{* *}(.014)$ & $-.088(.631)$ & & $.362^{* *}(.033)$ & $.187(.430)$ \\
\hline
\end{tabular}

Note. The symbol "B" stands for traditional bank loans. The numbers in parentheses represent $\mathrm{p}$-values.

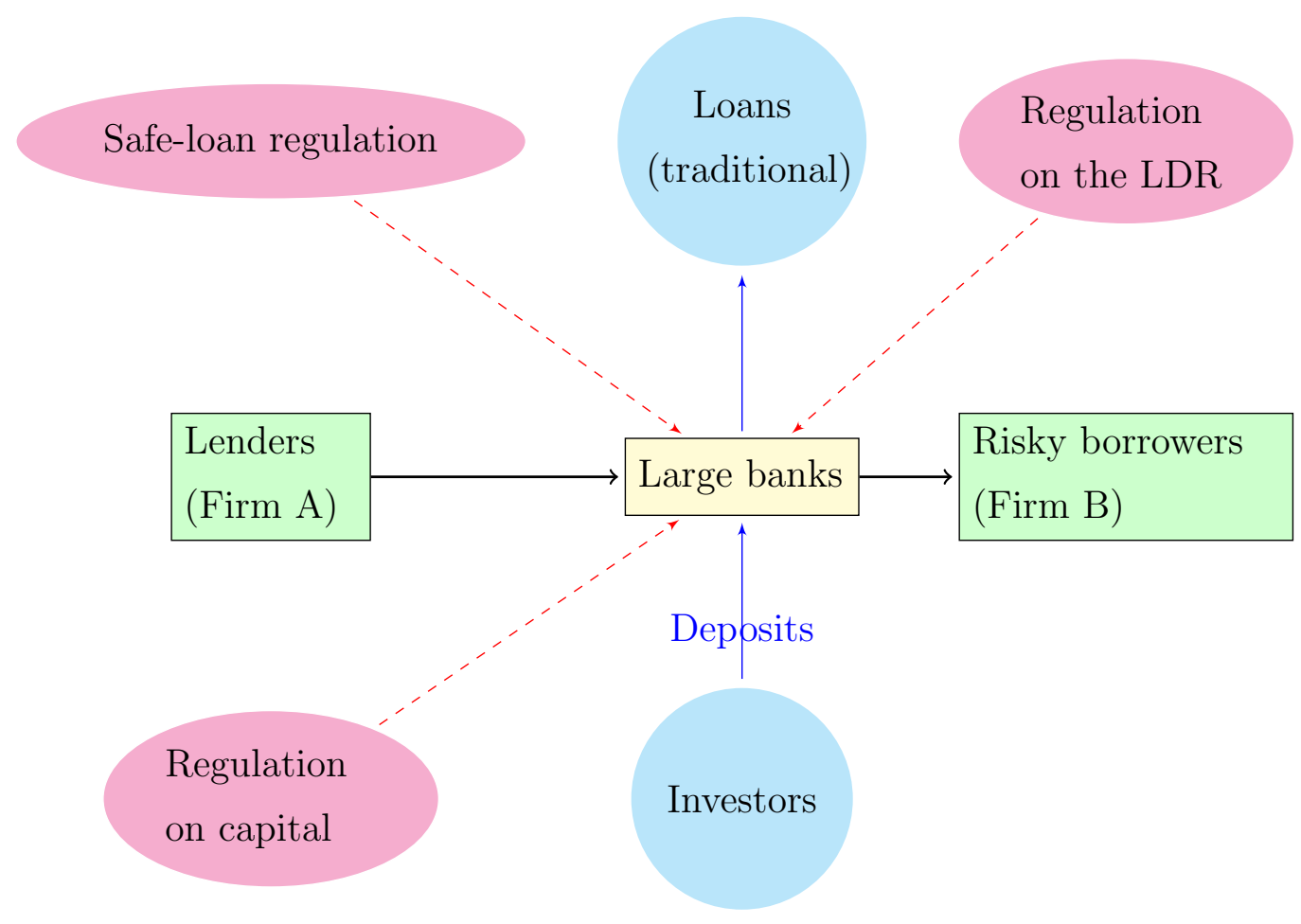

Figure 5. An illustration of the Chinese institutions for entrusted loans: how large banks channeled entrusted loans. "Safe-loan regulation" refers to a series of 2010-2013 laws that strictly banned commercial banks from expanding bank loans to the risky industry. The dashed lines originating from "Regulation on capital" and "Safe-loan regulation" indicate that these two regulations are far from binding. The dashed line originating from "Regulation on the LDR" indicates that there is no extra cost to comply with this regulation. See Section VI.5 for further discussions. 
While the correlations of overall entrusted lending with ARI are positive and significant for small banks but not for large banks, the question is whether this result holds for the correlations of risky entrusted lending and ARI. Table 15 reports such correlations for the same two periods. Clearly, the estimated correlations for small banks continue to be positive and statistically significant; again, the estimates are statistically insignificant for large banks. This striking finding is confirmed by the government's concern that commercial banks, especially small ones, have taken balance-sheet risks by providing implicit and explicit guarantees to entrusted lending, where the explicit guarantees were in the form of entrusted rights. So grave was the concern that the government in 2014 made it illegal for banks to mask the balance-sheet risk "through the channel of entrusted lending."

The above empirical finding reveals that the linkage between entrusted loans and China's banking system has developed far beyond the basic structure displayed in Figure 3. Since traditional loans on banks' balance sheet were largely safe by regulations or by implicit guarantees of the government and since large banks were capable of weathering deposit shortfall with no extra cost, the behavior of large banks described by Figure 5 is in essence similar to the basic structure represented by Figure 3. The issue, however, lies in the risktaking behavior of small banks. As shown in Table 14, entrusted lending funneled by small banks is significantly and positively correlated with ARI, while the correlation does not exist or may even be negative for large banks. The extensive institutional structure for small banks' activity in entrusted lending is illustrated by Figure 6. Because of the disparity between small and large banks in costs of acquiring additional deposits under the pressure of deposit shortfalls, we show in Section VI that a combination of the LDR and safe-loan regulations gives small banks a wrong incentive to take on risky nonloan investment through regulatory arbitrage.

\section{A theoretical model AGAinst the Unique institutional BACKGRound}

Below we build a tractable equilibrium model, grounded in Chinese institutional details, for understanding how the behavior of Chinese banks influences their optimal portfolio choice under the constraint of both LDR and safe-loan regulations. We then discuss how our model predictions are consistent with our empirical findings.

VI.1. Environment. There are two types of banks, large and small, distinguished only by the costs of meeting unexpected deposit shortfalls that threaten to violate the LDR ceiling 


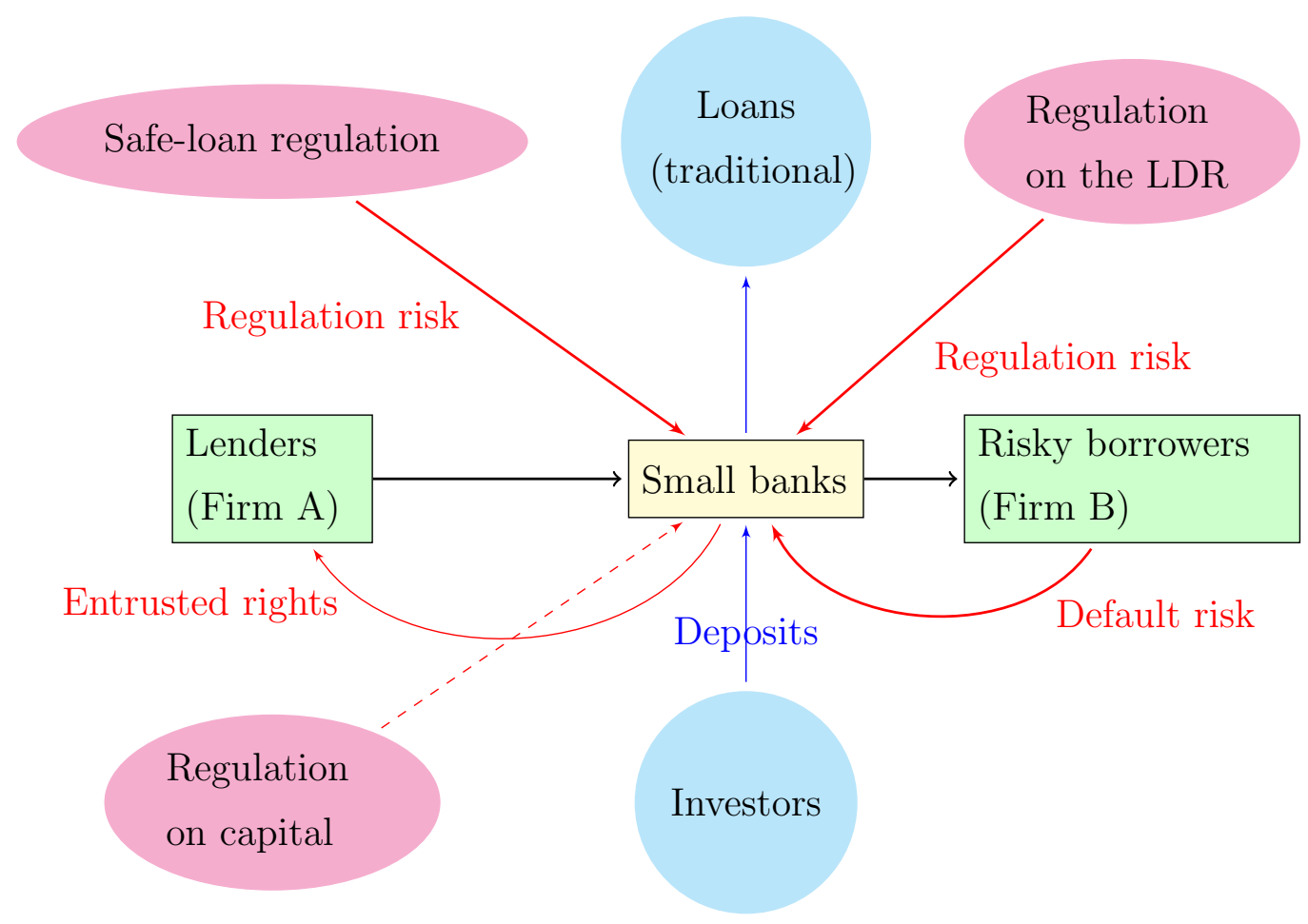

FiguRe 6. An illustration of the Chinese institutions for entrusted loans: how small banks funneled entrusted loans and what were the associated risks. "Entrusted rights" refers to investment in purchases of beneficiary rights of entrusted loans. "Safe-loan regulation" refers to a series of 2010-2013 laws that strictly banned commercial banks from expanding bank loans to the risky industry. The dashed line indicates that the current capital requirement regulation is far from binding. See Section VI.5 for further discussions.

constraint. Although all banks face the same LDR regulation, large banks, being stateowned, pay no extra cost to recoup deposit losses. Small banks, on the other hand, have to pay extra costs to recover temporary deposit shortfalls. There is an aggregate shock that increases a withdrawal risk to deposits in all banks. ${ }^{20}$ For simplicity, both large and small banks face the same deposit withdrawal risk, an assumption that is consistent with the evidence provided by the PBC's various Financial Stability Reports on the monthly deposit volatilities across different types of banks.

\footnotetext{
${ }^{20}$ This assumption is consistent with the facts presented in Figure 1. Aggregate shocks that contract monetary aggregates tend to increase pressures on deposit withdrawals and as a result contract deposits. Our model abstracts from trend growth by assuming that any changes are deviations from trend.
} 
The bank has three types of assets: (i) cash, (ii) traditional loans $\left(B_{t}\right)$ subject to the safe-loan regulation as well as regulation risks associated with random deposit shortfalls, and (iii) risky nonloan assets $\left(I_{t}^{r}\right)$ subject to the default risk but not to the regulation risks as $I_{t}^{r}$ are not counted as part of $B_{t}$ according to the LDR regulation. Given the deposits, the bank makes an optimal portfolio choice between safe loans and risky assets. Within each period, banking activities for both types of banks involve two stages: a lending stage and a balancing stage.

VI.2. Lending stage. At the lending stage, the representative small bank decides how much deposit to demand, how much dividend to distribute, and how to allocate three types of assets for investment: intertemporal safe bank loans (longer term), within-period risky shadow assets (shorter term), and cash. ${ }^{21}$ Bank loans, $B_{t}$, are safe (default free) but subject to the regulatory constraint on the LDR, and are purchased at a discount price $q_{t}$. Risky assets, $I_{t}^{r}$, have a default probability $p^{r}$ and are purchased at a discount price $0<q_{t}^{r}<1$.

The law of motion for bank loans evolves as

$$
\tilde{B}_{t}=\delta B_{t}+S_{t}
$$

where $(1-\delta) B_{t}$ represents a fraction of loans that is retired and $S_{t}$ represents new safe loans made by the bank to comply with the safe-loan regulation. Denote cash by $C$ and

$$
\tilde{C}_{t}=C_{t}+\varphi_{t}
$$

where $\varphi_{t}$ represents additional cash holdings chosen by the bank.

At the beginning of the period, the bank's balance-sheet constraint is

$$
D_{t}+\mathscr{E}_{t}=\underbrace{C_{t}+(1-\delta) B_{t}}_{\text {new cash }}+q_{t} \delta B_{t}
$$

where $D_{t}$ represents deposits and $\mathscr{E}_{t}$ the bank's equity or capital. Table 16 or Table 17 , below, represents the balance sheet in which the left hand column indicates the asset side and the right hand column the liability side.

The bank's balance-sheet constraint, after choosing $\tilde{C}_{t}\left(\right.$ or $\varphi_{t}$ ), $I_{t}^{r}, \tilde{B}_{t}\left(\right.$ or $\left.S_{t}\right), \tilde{D}_{t}$, and dividend $\mathrm{DIV}_{t}$, is

$$
\tilde{D}_{t} / R_{t}^{D}+\mathscr{E}_{t}-\operatorname{DIV}_{t}=\tilde{C}_{t}+q_{t}^{r} I_{t}^{r}+q \tilde{B}_{t}
$$

\footnotetext{
${ }^{21}$ The maturities assumed for bank loans and risky assets capture the essence of our empirical finding that risky assets tend to have a shorter maturity than safe assets (see Section IV.1). This assumption, along with other assumptions in the rest of the analysis, is made to keep our model tractable for obtaining intuitive results.
} 
TABLE 16. Balance sheet at the beginning of the period

\begin{tabular}{|c||c|}
\hline Assets & Liabilities \\
\hline \hline Cash $\left(C_{t}+(1-\delta) B_{t}\right)$ & Deposits $\left(D_{t}\right)$ \\
Loans $\left(q_{t} \delta B_{t}\right)$ & Equity $\left(\mathscr{E}_{t}\right)$ \\
\hline
\end{tabular}

TABLE 17. Balance sheet at the beginning of the period

\begin{tabular}{|c||c|}
\hline Assets & Liabilities \\
\hline \hline Cash $\left(C_{t}\right)$ & Deposits $\left(D_{t}-(1-\delta) B_{t}\right)$ \\
Loans $\left(q_{t} \delta B_{t}\right)$ & Equity $\left(\mathscr{E}_{t}\right)$ \\
\hline
\end{tabular}

which leads to

$$
\underbrace{\tilde{D}_{t} / R_{t}^{D}}_{\text {deposits }}+\underbrace{\mathscr{E}_{t}-\mathrm{DIV}_{t}+\left(1-q_{t}^{r}\right) I_{t}^{r}+\left(1-q_{t}\right) \tilde{B}_{t}}_{\text {equity }}=\underbrace{\tilde{C}_{t}}_{\text {cash }}+\underbrace{I_{t}^{r}+\tilde{B}_{t}}_{\text {assets }},
$$

where $R_{t}^{D}$ is the deposit rate. The balance sheet now becomes Table 18 .

TABLE 18. Balance sheet after the bank's optimization

\begin{tabular}{|c||c|}
\hline Assets & Liabilities \\
\hline \hline Cash $\left(\tilde{C}_{t}\right)$ & Deposits \\
\cline { 1 - 1 } Risky assets & $\tilde{D}_{t} / R_{t}^{D}$ \\
\cline { 2 - 2 }$I_{t}^{r}$ & Equity \\
Safe loans & $\mathscr{E}_{t}-\operatorname{DIV}_{t}+$ \\
$\tilde{B}_{t}$ & $\left(1-q_{t}^{r}\right) I_{t}^{r}+\left(1-q_{t}\right) \tilde{B}_{t}$ \\
\hline
\end{tabular}

Substituting (9), (10), and (11) into (13) gives us the flow-of-funds constraint as

$$
\underbrace{\tilde{D}_{t} / R_{t}^{D}-D_{t}}_{\Delta \text { deposits }}+\underbrace{\left(1-q_{t}^{r}\right) I_{t}^{r}+\left(1-q_{t}\right) S_{t}-\mathrm{DIV}_{t}}_{\Delta \text { equity }}=\underbrace{\varphi_{t}+I_{t}^{r}+\left(\tilde{B}_{t}-B_{t}\right)}_{\Delta \text { assets }} .
$$

The standard credit constraint is

$$
\tilde{D}_{t} / R_{t}^{D} \leq \kappa\left[\mathscr{E}_{t}-\mathrm{DIV}_{t}\right]
$$

where $\kappa$ is the leverage ratio and the term in brackets after $\kappa$ represents the equity after the dividend payout. 
VI.3. Balancing stage. At the balancing stage, two random events occur. First, all banks (large and small) are subject to idiosyncratic withdrawal shocks to deposits. The idiosyncratic risk is represented by $\omega_{t}$ such that

$$
\omega_{t}= \begin{cases}\omega^{h} & \text { with probability } p_{t}^{\omega} \\ \omega^{l} & \text { with probability } 1-p_{t}^{\omega}\end{cases}
$$

where $\omega^{h}>\omega^{l}$. To obtain a closed-form solution for intuitive results, we simplify the withdrawal risk distribution (16) by letting $\omega^{h}=1$ and $\omega^{l}=0 .{ }^{22}$ Second, risky assets are defaulted with probability $p^{r}$.

The amount of bank loans is subject to the LDR regulation as

$$
q_{t} \tilde{B}_{t} \leq \theta \frac{\left(1-\omega_{t}\right) \tilde{D}_{t}}{R_{t}^{D}}
$$

where $\theta$ is the LDR ceiling set by the PBC. Denote

$$
\tilde{x}_{t}=q_{t} \tilde{B}_{t}-\theta \frac{\left(1-\omega_{t}\right) \tilde{D}_{t}}{R_{t}^{D}}
$$

and

$$
\chi\left(\tilde{x}_{t}\right)=\left\{\begin{array}{ll}
r_{t}^{b} \tilde{x}_{t} & \text { if } \tilde{x}_{t} \geq 0 \\
0 & \text { if } \tilde{x}_{t}<0
\end{array},\right.
$$

where $r_{t}^{b}>0$ is the extra cost of obtaining additional deposits $\tilde{x}_{t}$. For clear illustration, we assume $r_{t}^{b}=0$ for large banks to capture the fact that these banks can weather deposit fluctuations with no extra costs. It is straightforward to show that large banks' portfolio choice is indifferent to safe loans and risky investment (after adjusting for the risk premium). Thus, the rest of the analysis is about small banks. Unless indicated otherwise, the word "bank" is shorthand for "small bank" in Section VI.

If default on $I_{t}^{r}$ (risky assets) does not occur (in the no-default state), one can derive from equation (13) the balance-sheet constraint for the bank as

$$
\underbrace{\tilde{D}_{t} / R_{t}^{D}-I_{t}^{r}}_{\text {debt reduction }}+\underbrace{\mathscr{E}_{t}-\mathrm{DIV}_{t}+\left(1-q_{t}^{r}\right) I_{t}^{r}+\left(1-q_{t}\right) \tilde{B}_{t}}_{\tilde{E}_{t} \text { : equity }}=\underbrace{\tilde{C}_{t}+\tilde{B}_{t}}_{\text {assets }} .
$$

\footnotetext{
${ }^{22}$ One can see from Appendix C.3 that bank deposits decline when $p^{\omega}$ increases, consistent with the empirical observation that monetary aggregates and bank deposits in China comove. Under regularity conditions, our results hold for a more complicated distribution for $\omega_{t}$. A general distribution takes the form of a cumulative density function $\mathscr{F}_{t}\left(\omega_{t}\right)$ and the corresponding probability density function $\mathfrak{f}_{t}\left(\omega_{t}\right)$. The derived mathematical expressions, however, would be unnecessarily complex at the expense of obscuring the intuition.
} 
If $I_{t}^{r}$ is defaulted (in the default state), the bank's balance-sheet constraint becomes

$$
\underbrace{\tilde{D}_{t} / R_{t}^{D}}_{\text {liabilities }}+\underbrace{\mathscr{E}_{t}-\mathrm{DIV}_{t}-q_{t}^{r} I_{t}^{r}+\left(1-q_{t}\right) \tilde{B}_{t}}_{\tilde{\tilde{E}}_{t} \text { : equity }}=\underbrace{\tilde{C}_{t}+\tilde{B}_{t}}_{\text {assets }} .
$$

Since $\tilde{\tilde{E}}_{t}=\tilde{E}_{t}-I_{t}^{r}$, the bank's equity is reduced in the default state. At the end of period $t$ (the beginning of period $t+1$ ), the stock variables are balanced as

$$
\begin{gathered}
D_{t+1}=\tilde{D}_{t}\left(1-\omega_{t}\right)+\chi\left(\tilde{x}_{t}\right)-\frac{\varepsilon_{t} R_{t+1}^{D} I_{t}^{r}}{q_{t}^{r}}, \\
C_{t+1}=\tilde{C}_{t}-\omega_{t} \tilde{D}_{t} \\
B_{t+1}=\tilde{B}_{t}
\end{gathered}
$$

where

$$
\varepsilon_{t}=\left\{\begin{array}{l}
1 \quad \text { with probability } 1-p^{r} \text { (the no-default state) } \\
0 \quad \text { with probability } p^{r} \text { (the default state) }
\end{array}\right.
$$

VI.4. The bank's optimizing problem. The bank's optimizing problem is complex. To maintain tractability, we simplify the liability-side behavior as it is not a focus of our model. ${ }^{23}$ The asset-side story, motivated by China's institutional arrangements and our empirical evidence, is a central piece of our theory. To avoid notational glut and make our theory transparent, we omit the time subscript whenever no confusion arises. The optimizing behavior at the lending stage can thus be described as

$$
V^{l}(C, B, D ; z)=\max U(\mathrm{DIV})+E_{\omega, \varepsilon}\left[V^{b}(\tilde{C}, \tilde{B}, \tilde{D} ; z)\right]
$$

where $z=\left\{r^{b}, p^{\omega}, q, q^{r}, R^{D}\right\}, V^{l}$ is the value function at the lending stage, $V^{b}$ is the value function at the balancing stage, and $E_{\omega, \varepsilon}$ is the mathematical expectation with respect to the $(\omega, \varepsilon)$ measure. By choosing (DIV, $\left.\varphi, S, I^{r}\right)$, the bank solves the above problem subject to

$$
\begin{gathered}
\tilde{D} / R_{t}^{D}=D-(1-\delta) B+\mathrm{DIV}+\varphi+q^{r} I^{r}+q S \\
\tilde{C}=C+\varphi \\
\tilde{B}=\delta B+S \\
\tilde{D} / R^{D} \leq \kappa\left[\tilde{C}+q^{r} I^{r}+q \tilde{B}-\tilde{D} / R^{D}\right]
\end{gathered}
$$

\footnotetext{
${ }^{23}$ See Hachem and Song (2015) for a detailed modeling of the bank's liabilities.
} 
where constraint (23) corresponds to (14); and constraint (26), derived from (13) and (15), represents the credit constraint on the bank's optimization problem.

The balancing-stage behavior can be described as

$$
V^{b}(\tilde{C}, \tilde{B}, \tilde{D} ; z)=\beta E_{M}\left[V^{l}\left(C^{\prime}, B^{\prime}, D^{\prime} ; z^{\prime}\right) \mid z\right]
$$

subject to

$$
\begin{gathered}
D^{\prime}=(1-\omega) \tilde{D}+\chi(\tilde{x})-\frac{\varepsilon R^{D^{\prime}} I^{r}}{q^{r}}, \\
C^{\prime}=\tilde{C}-\omega \tilde{D} \\
B^{\prime}=\tilde{B} \\
\tilde{x}=q \tilde{B}-\theta(1-\omega) \tilde{D} / R^{D}
\end{gathered}
$$

where $\beta$ is a subjective discount factor, $z^{\prime}=\left\{r^{b \prime}, p^{\omega \prime}, q^{\prime}, q^{r \prime}, R^{D \prime}\right\}$, and $E_{M}$ represents the mathematical expectation with respect to macroeconomic factors such as the risk of deposit withdrawal. Such factors determine how $z^{\prime}$ evolves conditioning on the realization of $z$. Constraints (27), (28), and (29) correspond to (20), (21), and (22); constraint (30) corresponds to $(17)$.

Combining the two stages, we can describe the overall optimization problem as

$$
\begin{aligned}
V^{l}(C, B, D ; z)=\max & U(\mathrm{DIV}) \\
+\beta E_{M, \omega, \varepsilon} & {\left[V^{l}\left(\tilde{C}-\omega \tilde{D}, \tilde{B},(1-\omega) \tilde{D}+\chi(\tilde{x})-\frac{\varepsilon R^{D^{\prime}} I^{r}}{q^{r}} ; \tilde{z}\right) \mid z\right] }
\end{aligned}
$$

subject to (23), (24), (25), and (26). The choice variables for this optimization are (DIV, $\left.\varphi, S, I^{r}\right)$. Given $\mathscr{E}=C+q \delta B-(D-(1-\delta) B)$, we have the following proposition:

Proposition 1. The optimization problem (31) can be simplified and collapsed into the singlestate representation

$$
V(\mathscr{E} ; z)=\max U(\mathrm{DIV})+\beta E_{M, \omega, \varepsilon}\left[V\left(\mathscr{E}^{\prime} ; z^{\prime}\right) \mid z\right]
$$

subject to (26), (30), and

$$
\begin{gathered}
\mathscr{E}-\mathrm{DIV}=\underbrace{\tilde{C}}_{\text {cash }}+\underbrace{q^{r} I^{r}+q \tilde{B}}_{\text {assets }}-\underbrace{\tilde{D} / R^{D}}_{\text {liabilities }}, \\
\mathscr{E}^{\prime}=\underbrace{\tilde{C}-\omega \tilde{D}}_{\text {cash }}+\underbrace{q^{\prime} \delta \tilde{B}+(1-\delta) \tilde{B}}_{\text {assets }}-\underbrace{\left[(1-\omega) \tilde{D}+\chi(\tilde{x})-\frac{\varepsilon R^{D \prime} I^{r}}{q^{r}}\right]}_{\text {liabilities }},
\end{gathered}
$$


where the single state is $\mathscr{E},(33)$ corresponds to (12), (34) is derived from (11), (20), (21), and (22) (by moving time $t$ in (11) forward to time $t+1$ ), and the choice variables are (DIV $\left., \tilde{C}, \tilde{B}, \tilde{D}, I^{r}\right)$.

Proof. See Appendix C.1.

Since constraints (26), (33), and (34) are linear in $\mathscr{E}$ and the objective function is homothetic in $\mathscr{E}$, the solution to the bank's problem not only exists but also is unique and the policy function is linear in equity $\mathscr{E}$. Moreover, thanks to the Principle of Optimality, the bank's dynamic problem can be separated into two subproblems, one concerning an intertemporal choice of dividend payoffs and the other relating to an intratemporal portfolio allocation. The following proposition formalizes these two results. ${ }^{24}$

Proposition 2. Let

$$
U(\mathrm{DIV})=\frac{\mathrm{DIV}^{1-\gamma}}{1-\gamma},
$$

where $\gamma \geq 1$. Optimization problem (32) satisfies the two properties: homogeneity in $\mathscr{E}$ and separability of portfolio choice from dividend choice.

- Homogeneity. The value function $V(\mathscr{E} ; z)$ is

$$
V(\mathscr{E} ; z)=v(z) \mathscr{E}^{1-\gamma}
$$

and $v(z)$ satisfies the Bellman equation over the choice variables $\left\{\operatorname{div}, \tilde{c}, i^{r}, \tilde{b}, \tilde{d}\right\}$

$$
v(z)=\max U(\operatorname{div})+\beta E_{M, \omega, \varepsilon}\left[v\left(z^{\prime}\right)\left(e^{\prime}\left(\omega, \varepsilon ; z^{\prime}, z\right)\right)^{1-\gamma} \mid z\right]
$$

subject to

$$
\begin{gathered}
\tilde{d} / R^{D} \leq \kappa\left[\tilde{c}+q^{r} i^{r}+q \tilde{b}-\tilde{d} / R^{D}\right] \\
1=\tilde{c}+\operatorname{div}+q^{r} i^{r}+q \tilde{b}-\tilde{d} / R^{D}, \\
e^{\prime}=\tilde{c}+\left(q^{\prime} \delta+1-\delta\right) \tilde{b}-\tilde{d}-\chi(q \tilde{d}-\theta(1-\omega) \tilde{d})+\frac{\varepsilon R^{D \prime} i^{r}}{q^{r}},
\end{gathered}
$$

where

$$
\left[\operatorname{div}, \tilde{c}, \tilde{b}, \tilde{d}, i^{r}, e^{\prime}\right]=\frac{\left[\operatorname{DIV}, \widetilde{C}, \widetilde{B}, \widetilde{D}, I^{r}, \mathscr{E} \prime\right.}{\mathscr{E}}
$$

\footnotetext{
${ }^{24}$ The homogeneity and separability properties in Proposition 2 are similar to Bianchi and Bigio (2014).
} 
- Separability. Problem (35) can be broken into two separate problems. The first problem is for banks to make an optimal portfolio choice, by choosing $\left\{w_{c}, w_{i}, w_{b}, w_{d}\right\}$ to maxmize the certainty-equivalent portfolio value, described as

$$
\Omega\left(z^{\prime}, z\right)=\max \left\{E_{\omega, \varepsilon}\left[w_{c}+R^{I} w_{i}+R^{B} w_{b}-R^{D} w_{d}-R^{x}\right]^{1-\gamma}\right\}^{\frac{1}{1-\gamma}}
$$

subject to

$$
\begin{gathered}
1=w_{c}+w_{i}+w_{b}-w_{d}, \\
w_{d} \leq \kappa\left(w_{c}+w_{i}+w_{b}-w_{d}\right),
\end{gathered}
$$

and taking the following prices as given

$$
R^{I}=\frac{\varepsilon R^{D}}{q^{r}}, R^{B}=\frac{q^{\prime}+1-\delta}{q}, R^{x}=\chi\left(w_{b}-\theta(1-\omega) w_{d}\right),
$$

where

$$
w_{\varsigma}=\frac{\varsigma}{1-\operatorname{div}}, \text { for } \varsigma=\tilde{c}, \tilde{d} / R, q^{r} i^{r}, q \tilde{b} .
$$

The second problem is to choose div in response to aggregate shocks, described as

$$
v(z)=\max _{\operatorname{div}} U(\operatorname{div})+\beta(1-\operatorname{div})^{1-\gamma} E_{M}\left[\Omega\left(z^{\prime}, z\right)^{1-\gamma} v\left(z^{\prime}\right) \mid z\right] .
$$

Proof. See Appendix C.2.

Note that equations (36), (37), and (38) are derived from equations (26), (33), and (34) and that $e^{\prime}$ is a function of $\omega, \varepsilon, z^{\prime}$, and $z$ such that

$$
e^{\prime}\left(\omega, \varepsilon ; z^{\prime}, z\right)=(1-\operatorname{div}) R^{E}\left(\omega, \varepsilon ; z^{\prime}, z\right)
$$

where $R^{E}$ is the return to bank's equity after divident payout

$$
R^{E}\left(\omega, \varepsilon ; z^{\prime}, z\right)=w_{c}+R^{I} w_{i}+R^{B} w_{b}-R^{D} w_{d}-\chi\left(w_{b}-\theta(1-\omega) w_{d}\right) .
$$

Proposition 2 breaks the potentially unmanageable problem into two tractable problems by separating dividend decision about DIV in response to aggregate shocks from portfolio choice about $\varphi, S, I^{r}$, and $\tilde{D}$ in response to idiosyncratic risks. This technical advancement enables us to establish the following substantive proposition.

Proposition 3. As $p^{\omega}$ increases, the bank's optimal portfolio choice is such that

(i) the share of risky assets in total assets $\frac{q^{r} I^{r}}{q^{r} I^{r}+q B^{\prime}}$ increases, i.e., $\partial \frac{q^{r} I^{r}}{q^{r} I^{r}+q B^{\prime}} / \partial p^{\omega}>0$;

(ii) the amount of risky assets $q^{r} I^{r}$ increases, i.e., $\partial\left(q^{r} I^{r}\right) / \partial p^{\omega}>0$.

Proof. See Appendix C.3. 
The theory developed thus far, especially Proposition 3, provides a coherent explanation of the "conspicuous phenomenon" illustrated by Figure 2. It also provides a general and tractable framework for studying the optimal but risk-taking behavior of small banks. According to Proposition 3, the optimal portfolio decision leads to an increase of investment in risky assets under monetary tightening for small banks and thus provides a theoretical underpinning of our empirical findings. The intuition for this powerful result comes from the asset-pricing equation governing a tradeoff between safe bank loans and risky nonloan investment $^{25}$

$$
E_{\varepsilon}\left(R^{I}\right)-\underbrace{\left[-\frac{\operatorname{Cov}_{\varepsilon}\left(R^{I}, E_{\omega}\left(R^{E}\right)^{-\gamma}\right)}{E_{\varepsilon}\left[E_{\omega}\left(R^{E}\right)^{-\gamma}\right]}\right]}_{\text {default risk premium }}=R^{B}-\underbrace{E_{\omega}\left[R_{b}^{x}\left(w_{b}, w_{d} ; \omega\right)\right]}_{\text {expected regulation cost }}
$$

where $R_{b}^{x}\left(w_{b}, w_{d} ; \omega\right)$ is the partial derivative of $R^{x}\left(w_{b}, w_{d} ; \omega\right)$ with respect to safe loans:

$$
R_{b}^{x}\left(w_{b}, w_{d} ; \omega\right)=\frac{\partial R^{x}\left(w_{b}, w_{d} ; \omega\right)}{\partial w_{b}} .
$$

In the asset-pricing equation (47), the left-hand-side term is the expected return on risky investment, adjusted for the risk premium due to the default risk. The right-hand-side term is the expected return on safe bank loans, adjusted for the expected regulation cost. The risk premium is always positive. The expected regulation cost, also positive, is the expected marginal cost associated with the lending amount $B$ subject to the LDR regulation. This term captures the extra cost of recovering deposit shortfalls. When the risk of deposit shortfalls rises, the expected regulation cost increases and so does the return on risky investment relative to the return on bank loans. Thus, small banks have an incentive to rebalance the portfolio by increasing the share of risky assets in total assets.

For the asset-pricing equation (47) to hold, the necessary and sufficient condition is

$$
E_{\varepsilon}\left(R^{I}\right)>R^{B}-r^{b} p^{w}
$$

where $r^{b} p^{w}=E_{\omega}\left(R_{b}^{x}\right)$ is the expected regulation cost. Equation (48) states that the expected return on risky investment is greater than the effective return on bank loans such that the bank has an incentive to invest in risky assets, even if the bank is risk-averse. Thus, the asset-pricing equation implies that it is optimal for the bank to increase the share of risky assets in its total investment on the asset side of the balance sheet.

\footnotetext{
${ }^{25}$ See Appendix C.3 for the derivation of this condition.
} 
Not only does theory predict a rise of the share of risky assets for any fixed amount of total investment, it also predicts another powerful result: investment in risky assets increases in absolute terms. The proof of this result is more involved (see Appendix C.3), but the intuition can be clearly laid out. Consider a low deposit rate such that

$$
R^{D}<R^{B}-r^{b} p^{w}
$$

That is, the borrowing cost $R^{D}$ is lower than the effective return on bank loans. The low borrowing cost is a unique Chinese institutional feature that the deposit rate imposed by the government was kept artificially low. ${ }^{26}$ Such a low borrowing cost makes it optimal for the bank to leverage to the maximum; as a result, the credit constraint (15) or (26) is always binding. In our theoretical model, when the risk to deposit withdrawal increases at the lending stage, the expected net return for leverage adjusted for the risk premium becomes greater than $R^{D}$ (see equations (48) and (49)). It is therefore profitable to borrow as much as possible by increasing $\tilde{D}$ until the credit constraint binds. The resource from the increased borrowing goes to risk assets to compensate for the costs associated with actual withdrawals in the balancing stage.

Economically, when the income effect of a reduction in the expected return on equity $\left(E_{\omega, \varepsilon} R^{E}\right)$ due to an increase in the expected regulation cost dominates the corresponding substitution effect (the substitution between today's and tomorrow's dividend payoffs), it is optimal for the small bank to raise risky investment to compensate extra costs of recouping deposit losses. This can be seen from (12) in which the left-hand-side term increases because $\mathrm{DIV}_{t}$ falls. This increase, together with the increase in the share of risky assets in response to monetary tightening, implies that $q_{t}^{r} I_{t}^{r}$ must increase.

In summary, the amount of risky investment increases during the period of monetary tightening because risky investment is an effective tool to compensate an increase in the expected regulation cost due to unexpected deposit losses. By purchasing entrusted rights the small bank receives a higher expected return on this nonloan investment, thereby killing two birds with one stone as discussed in the Introduction. In effect, investment in risky nonloan assets allows the small bank to exploit regulatory arbitrage because this risky investment is not subject to the safe-loan regulation that explicitly bans bank lending to the risky industry nor to the LDR regulation.

\footnotetext{
${ }^{26}$ On 23 October 2015 the PBC decided to remove the deposit rate ceiling.
} 
VI.5. Further discussions. In the above theory, the necessary and sufficient condition for small banks to increase investment in risky assets relative to safe loans is

$$
E_{\varepsilon}\left(R^{I}\right)>R^{B}-\text { Expected regulation cost. }
$$

That is, the expected return to risk assets must be greater than the effective return on bank loans. This important condition is supported by the data reported in Table 19, whereby the interest rate on risky entrusted loans was substantially higher than the interest rate on non-risky entrusted loans, which in turn was higher than the interest rate on bank loans in 2007-2013 and in 2010-2013. The interest rate on bank loans is the one-year base lending rate set by the $\mathrm{PBC}$. The reported interest rates on entrusted loans, risky or not, are not adjusted for maturity or the term premium. The interest rate spread between risky entrusted lending and bank lending, however, has a similar magnitude after we control for maturity by using a method similar to equation (1).

TABLE 19. Interest rates of risky and non-risky loans across different samples

\begin{tabular}{|c||c|c|}
\hline Description & $2007-2013$ & $2010-2013$ \\
\hline Bank loans & $6.16 \%$ & $6.00 \%$ \\
Non-risky entrusted loans & $7.92 \%$ & $7.71 \%$ \\
Risky entrusted loans & $9.22 \%$ & $9.05 \%$ \\
\hline
\end{tabular}

There are two competing hypotheses about the effect of entrusted lending. The first hypothesis that banks were supposed to act only as trustees or middlemen without bearing any credit risks on their balance sheet as indicated in Figure 3. This hypothesis was true only on paper, but in practice banks, especially small banks, were prone to funnel risky entrusted loans during the period of monetary tightening. Our empirical and institutional analyses support a competing hypothesis that such a risk-taking perchant for funneling entrusted loans to the real estate and overcapacity industries threatened the health of the banking system. The size of small banks as a whole was no small potatoes; the capital size (equity) of small banks as a whole accounted for $39 \%$ of the total capital for all commercial banks for the periods 2007-2013 and 2010-2013. Figure 6 describes the mechanism of how the risks were transmitted to small banks' balance sheet through shadow loans. As discussed in Section V, it is the unique institutional asymmetry between large and small banks that made a Chinese small bank willing to take on risky investment. This asymmetry is precisely the 
difference between large and small banks in costs of meeting deposit shortfalls when there are aggregate negative shocks that cause unexpected declines in deposits.

The risk spillover from shadow loans to banks' balance sheet began to be recognized by both G20's Financial Stability Board and various Chinese authorities in late 2013 and early 2014. ${ }^{27}$ Their concerns about the spillover were so grave that the Chinese government took concrete steps after the first quarter of 2014, by issuing and then implementing new regulations specifically designed to curb the risk-taking behavior of banks' participation in entrusted lending. On 29 April 2014 the CBRC held a state-wide official meeting on "Financial and Economic Analyses," identifying "nonstandard assets" as a threat to the health of the financial system and specifically outlining steps in containing the riskiness of entrusted lending and entrusted rights in the banking system. ${ }^{28}$ In particular, the specific rules outlined in the meeting prohibit banks from providing implicit or explicit guarantees of risky entrusted lending and from purchasing entrusted rights.

The cost disparity between large and small banks in attracting additional deposits under the pressure of deposit shortfalls against the LDR regulation is part of the driving force in our theory of the benefit of increasing nonloan investment in risky assets through regulatory arbitrage. The decree "Notice No. 236: On Strengthening Commercial Banks Deposit Stability Management" jointly issued on 12 September 12 by the CBRC, the Ministry of Finance, and the PBC effectively banned the practice of small banks in acquiring additional deposits through the WMP channel, by offering higher deposit rates, or through other highcost means. Perhaps realizing that this practice was not the only problem, the State Council passed a draft of the "People's Republic of China Commercial Bank Amendment Act" on 24 June 2015 to remove the LDR ceiling and thus officially ended this regulation that was enacted in 1995.

With all these changes, many more new regulations were enacted in 2015 for the purposes of insulating the banking system from being endangered by risky entrusted lending and more generally risky shadow banking. Yet the average capital adequacy ratio between 2010 and 2013 was almost the same for both large and small banks. On paper all Chinese banks met, by a large margin, the capital requirement $(8 \%)$ set by Basel III. A deeper analysis reveals a different story: risk weights assigned in calculation of the capital ratio may not adequately

\footnotetext{
${ }^{27}$ In 2009 the G20 countries created the Financial Stability Board from their previous financial stability forum to promote the goal of achieving global financial stability.

${ }^{28}$ Nonstandard assets include the WMPs, interbank businesses, trusted loans, entrusted loans, and investment in nonstandard claims (for example, entrusted rights purchased by banks).
} 
reflect the degree of riskiness expressed by China's various new regulations. For example, Basel III rules give a risk weight of $1250 \%$ to asset backed securities or structure securities to avoid the systemic risk. By contrast, Chinese banks assign only a 100\% risk weight to ARI, the same weight as that assigned to regular corporate loans. One can argue that entrusted rights in the category of $\mathrm{ARI}$ is in essence equivalent to an asset-backed security issued by lending firms with entrusted loans as backing assets. It is therefore likely that the risk weight for entrusted rights does not fully capture the degree of riskiness borne by such assets. With proper risk weights, the LDR and safe-loan regulations should be removed all together and the institutional asymmetry would have no place in helping create a wrong incentive for small banks, as illustrated by Figure 7. Future research on a proper regulatory design of risk weights for different categories of assets in Chinese banks, therefore, would prove fruitful and important to avoid the systemic risk.

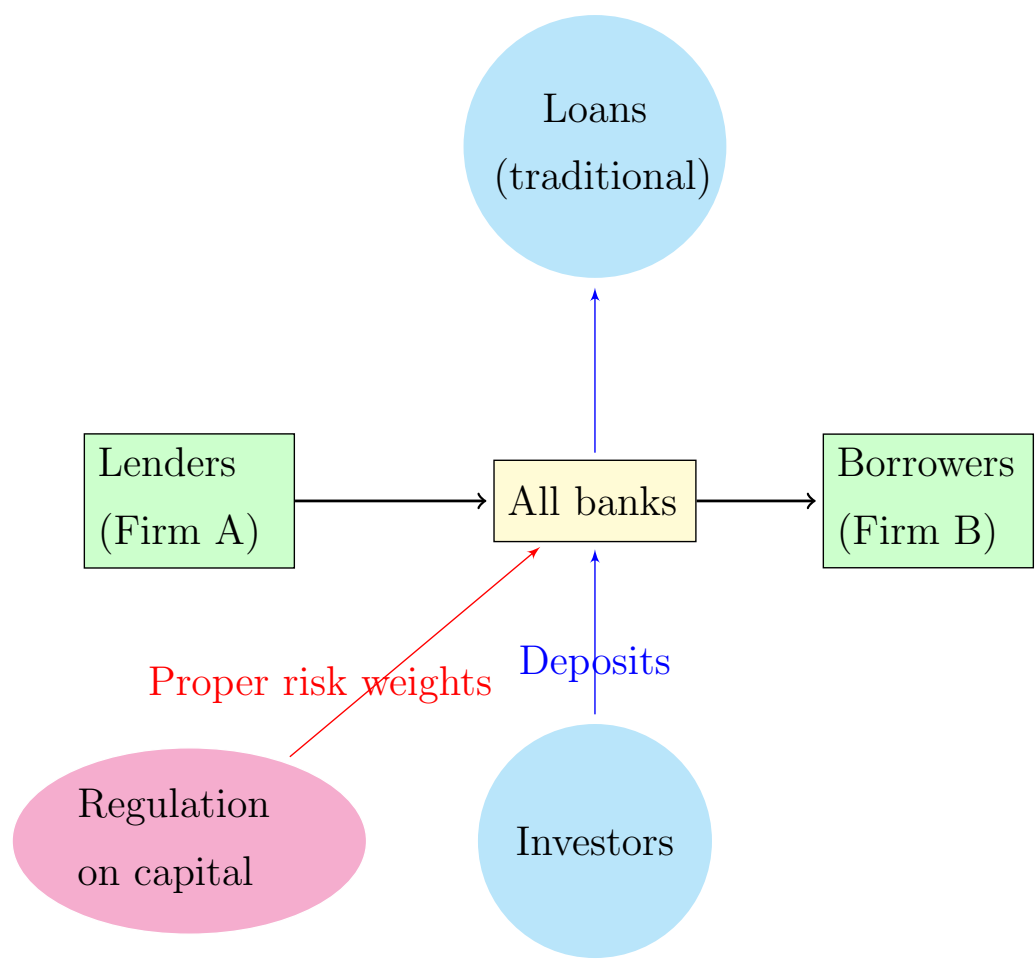

FiguRE 7. An illustration of how to regulate commercial banks with proper risk weights on different categories of assets as Chinese banks continue to facilitate entrusted loans as middlemen. 


\section{CONCLUSION}

Using our constructed micro data, we establish evidence that banks actively engaged in channeling risky entrusted loans during the period of monetary contractions. We argue that the LDR regulation, coupled with regulations prohibiting banks from making traditional loans to the risky industry, created an incentive for small banks to bring the risk of shadow loans into their balance sheet through regulatory arbitrage to compensate high costs of meeting random deposit shortfalls. Our study is a positive analysis, which delivers a concrete example of how well-intended regulations can lead to wrong incentives that may endanger the health of the banking system through shadow banking.

The period of monetary tightening and regulatory restrictions on commercial banks in our 2007-2013 sample offers a natural experiment to provide a positive analysis on the linkages between monetary policy, shadow banking, and traditional banking. Our empirical and theoretical findings demonstrate that banks' risk-taking behavior in funneling shadow loans was not just an isolated incident, but rather it foreshadowed how banks effectively used regulatory arbitrage to take on risks both on and off balance sheet. In particular, our positive analysis highlighted two specific loopholes of China's regulatory design that contributed to such risk-taking behavior. ${ }^{29}$

Since 2014 the Chinese government has taken concrete steps to enact and implement a host of new regulations in an effort to close such loopholes. In particular, these regulations prohibit banks from taking risks in entrusted lending either on or off balance sheet, to ban banks from paying higher prices than what regulations allowed to meet deposit shortfalls, and finally to remove the decades-long LDR regulation all together. In the context of these new and vigorous regulations, our postive study begets new and challenging normative questions. What is an effective and efficient way for the government to remove the institutional asymmetry between small and large banks? How should the government assign risk weights to various categories of assets, including securitized assets, in the capital requirement that accord with Basel III to avoid the systemic risk? How should the banking system be so reformed that commercial banks have a correct incentive to price the risks properly, especially

\footnotetext{
${ }^{29}$ There may be other potential regulatory loopholes that have allowed banks to mask credit risks by entrusted lending. A recent regulation called "On Commercial Banks' Practices of Managing Entrusted Lending: Open for Public Comment," issued by the CBRC on 16 January 2015, is an attempt to prohibit commercial banks from taking on credit risks through various means.
} 
those reflecting the risks specific to the Chinese economy? ${ }^{30}$ How should the regulators design an ambitious and comprehensive package of regulations for creating right incentives for commercial banks to invest and lend? How should the government design regulatory tools that are capable of taking into full account how the risks associated with individual banks might potentially cause the systemic financial risk triggered by, for example, the bank panic or fire sales of shadow assets. And how should monetary policy coordinate with regulatory policy in achieving an efficient but stable financial system? These and other important questions will undoubtedly enlarge the scope of this research and we hope that the steps taken in this paper will help foster further research on the effects of monetary and regulatory policies.

\footnotetext{
${ }^{30}$ In reality, although we observe that the interest rate charged to the risky industry is higher than the rate charged to other industries, the pricing might still fail to capture fully the underlying default risks due to implicit government guarantees to either banks or risky industries.
} 


\section{Appendix A. Data Appendix}

Given the large amount of data we have collected from various sources, we organize all the

variables used in this paper and the corresponding data sources in the table below. Unless we indicate CEIC or Bankscope, all other data sources come from WIND. 
TABLE 20. Variables and data sources

\begin{tabular}{|c|c|}
\hline Data source A & Data source B \\
\hline \hline M2 growth & Names of borrowers \\
Growth in aggregate bank loans & Names of lenders \\
Growth in aggregate bank deposits & Names of trustees \\
Aggregate newly originated bank loans & Transactions announced by lenders \\
Total social financing bar stocks and bonds & Transactions announced by borrowers \\
Aggregate entrusted lending & Date of each transaction \\
Aggregate trust lending & Amount of each transacted entrusted loan \\
Bank acceptances & Interest rate of each transacted entrusted loan \\
GDP growth & Maturity of each transacted entrusted loan \\
Inflation & Affiliated loans \\
7-day CHIBOR rate & Borrower's industry \\
One-year base lending rate & Data source D \\
\hline Data source C & Gross loan amount \\
\hline \hline Loan-to-deposit ratio & Total customer deposits \\
Capital adequacy ratio & Capital adequacy ratio \\
Excess reserves & Bank equity \\
Total deposits & Bank assets \\
\hline \hline Amount of bank lending & \\
Amount of account receivable investment & a \\
\hline \hline
\end{tabular}

Note: Data source A: CEIC. Data source B: announcements of entrusted loan transactions and annual reports of non-financial firms. Data source C: annual reports of listed commercial banks. Data source D: Bankscope (including non-listed banks). The variable "total deposits" from data source C is different from "total customer deposits" from data source D. Consistent with the PBC's requirements, "total deposits" is used to compute the reserve ratio while the loan-to-deposit ratio is computed as the ratio of "gross loan amount" and "total customer deposits". For the variable "capital adequacy ratio", we compare data sources $\mathrm{C}$ and $\mathrm{D}$ to make sure they match. 


\section{Appendix B. Regulation timeline ApPendix}

The list of descriptions, below, organizes all the regulations either explicitly discussed in the paper or relevant to the discussion.

\section{Regulations relevant to the discussions in the paper in chronological order}

LDR: 5/10/1995. "People's Republic of China Commercial Bank Law" passed by the National People's Congress. The law specified the $75 \%$ LDR ceiling.

Entrusted Loans: 8/1/1996. "General Rules for Loans" issued by the PBC. The regulation provided a definition of entrusted lending.

Entrusted Loans: 4/5/2000. "Notice on Issues Related to Practices of Commercial Banks In Entrusted Lending" issued by the PBC. In the notice, the PBC changed the approval system to the registration system for entrusted loans.

Disclosure Requirements: 12/1/2004. "Stock Listing Rules of the Shanghai Stock Exchange" issued by the Shanghai Stock Exchange. The rules required that a listed firm on Shanghai Stock Exchange must disclose every entrusted-loan transaction if the loan amount is larger than $10 \%$ of the firm's net assets, revenue, or profits.

Disclosure Requirements: 12/1/2004. "Stock Listing Rules of the Shenzhen Stock Exchange" issued by the Shenzhen Stock Exchange. The rules required that a listed firms on Shenzhen Stock Exchange must disclose every entrusted-loan transaction if the loan amount is larger than $10 \%$ of the firm's net assets, revenue or profits.

Disclosure Requirements: 10/27/2005. "China Securities Law" revised and passed by the Eighteenth Meeting of the Standing Committee of the Tenth National People's Congress. The law stated that listed firms must announce all major events which may have influenced their stock prices. This law applied to all listed firms that engaged in entrusted-loan transactions.

Risky Industry: 5/28/2010. "Notice on Financial Services to Further Support Energy Saving and Eliminate Backward-Production Capacity" issued jointly by the PBC and CBRC. This regulation reinforced the 2006 notice issued by the State Council to make it operational to prohibit banks from originating new bank loans to the risky industry.

Risky Industry: 6/12/2010. "Reply to Number 001443 Proposal of the Third Session of the Eleventh National People's Congress" issued by the CBRC. The reply stressed 
the need to continue curtailing expansion of traditional bank credits to the risky industry.

Risky Industry: 8/8/2010. "Number 111 Announcement on the Manufacturing Industry" issued by China's Ministry of Industry and Information Technology. The announcement specifically classified the 18 overcapacity industries and reinforced the restriction of new bank credits to these industries.

Disclosure Requirements: 8/18/2010. "Memorandum of Information Disclosure for Small and Medium-Sized Enterprises" issued by Shenzhen Stock Exchange. The memo required that a listed firm must disclose information of entrusted loans as long as its subsidiary firm was a lender of these loans, even if the company itself was not a direct lender.

LDR: 1/1/2011. "CARPALS Supervision System" announced by the CBRC. The announcement provided 13 supervised indicators such as loan-to-deposit ratio and capital adequacy ratio and recommended that the PBC shall begin to monitor the LDR during the course of the year (quarterly) rather than at the end of the year.

Entrusted Loans: 2/9/2011. "Notice on Further Promoting Reforms and Development and on Strengthening Risk Management" issued by the CBRC. Item 6 in this notice regulated how the businesses of "shadow banks" should operate and recognized a possibility of regulatory arbitrage by stating "when off-balance-sheet assets are brought into balance sheet, banks must calculate all relevant indicators such as leverage ratio and capital adequacy ratio."

Risky Industry: 6/23/2011. "Conference on the Bellwether Series" held in China and organized by The Economist. An official from the CBRC who attended the conference stated the CBRC's requirement that commercial banks must continue to curtail bank loans to the real estate.

Disclosure Requirements: 6/29/2011. "Memorandum of Information Disclosure for Shenzhen Stock Exchange" issued by Shenzhen Stock Exchange. The memo re-emphasized that a listed firm must disclose information of entrusted loans as long as its subsidiary firm was a lender of entrusted loans, even if the company itself was not a direct lender.

Disclosure Requirements: 1/1/2012. "Rules for Information Disclosure By Companies Offering Securities to the Public" issued by China's Securities Regulatory Commission. The rules reinforce the requirement that every listed firm has the obligation to disclose all entrusted-loan transactions. This law is still in effect. 
Risky Industry: 7/5/2013. "Guidelines for Financial Support of Economic Structure Adjustments and for Transformation and Upgrade of the Insurance Industry" issued by the State Council. These guidelines reiterated the law that prohibited banks from providing new credits to the risky industry.

Shadow Banking: 12/10/2013. "Notice on Issues of Tightening Regulations on Shadow Banking" issued by the State Council. The notice mentioned possible regulatoryarbitrage problems associated with shadow banking, suggested the potential systemic risk caused by shadow banking, and tightened regulations on the shadow banking system including entrusted loans.

Nonstandard Assets: 4/29/2014. "Official Meeting on Financial and Economic Analyses" held by the CBRC. The meeting identified "nonstandard assets" as a threat to the health of the financial system and specifically outlining steps in containing the riskiness of entrusted lending and entrusted rights in the banking system.

Last-Minute Rush: 9/12/2014. "Number 236 Notice on Strengthening Commercial Banks Deposit Stability Management" issued jointly by CBRC, the Ministry of Finance, and the PBC. The notice identified last-minute actions taken by banks to pay high prices to artificially increase temporary deposits in order to recoup deposit shortfalls when the PBC's deposit-monitoring time was near. While the notice applied to all banks, it effectively banned the practice of small banks in acquiring additional deposits through the WMP channel, by offering higher deposit rates, or through other high-cost means.

Entrusted Loans: 1/16/2015. "Draft for Management Rules on Commercial Banks' Entrusted Loans: Open for Public Opinions" issued by the CBRC. The draft reinforced the earlier regulations that commercial banks were prohibited from taking on credit risks when facilitating entrusted loans.

LDR Ceiling Removal: 6/24/2015. "People's Republic of China Commercial Bank Law Amendment (Draft)" proposed by the State Council on that day and approved by the Standing Committee of the National People's Congress on 20 August 2015. It removed the LDR ceiling and thus officially ended this regulation enacted in 1995.

Deposit Rate Ceiling Removal: 10/24/2015. "Notice on the Removal of Deposit Rate Ceiling of Commercial Banks" issued by the PBC. The notice removed the ceiling of bank deposit rates. 


\section{Appendix C. Technichl appendix: proofs of Propositions 1-3}

C.1. Proof of Proposition 1. The proof for Proposition 1 follows from the fact that $\mathscr{E}$ is a sufficient statistics for the bank's problem. In other words, once $\mathscr{E}$ is determined, the bank's optimal decision does not depend on the sources from which the equity $\mathscr{E}$ is accumulated.

C.2. Proof of Proposition 2. Homogeneity: We use the conjecture-verify approach to this complicated problem. We conjecture the form of the value function as

$$
V(\mathscr{E} ; z)=v(z) \mathscr{E}^{1-\gamma}
$$

Because

$$
\mathscr{E}^{\prime}=e^{\prime}\left(\omega, \varepsilon ; z^{\prime}, z\right) \mathscr{E}
$$

the optimization problem (32) can be rewritten as

$$
\begin{aligned}
V(\mathscr{E} ; z) & =\max U(\operatorname{div} \mathscr{E})+\beta E_{M, \omega, \varepsilon}\left[v\left(z^{\prime}\right)\left(e^{\prime}\left(\omega, \varepsilon ; z^{\prime}, z\right) \mathscr{E}\right)^{1-\gamma} \mid z\right] \\
& =\mathscr{E}^{1-\gamma}\left\{\max U(\operatorname{div})+\beta E_{M, \omega, \varepsilon}\left[v\left(z^{\prime}\right)\left(e^{\prime}\left(\omega, \varepsilon ; z^{\prime}, z\right)\right)^{1-\gamma} \mid z\right]\right\}
\end{aligned}
$$

subject to (36), (37), and (38). Let $\tilde{v}(z)$ be the solution of

$$
\tilde{v}(z)=\max U(\operatorname{div})+\beta E_{M, \omega, \varepsilon}\left[\tilde{v}\left(z^{\prime}\right)\left(e^{\prime}\left(\omega, \varepsilon ; z^{\prime}, z\right)\right)^{1-\gamma} \mid z\right]
$$

subject to (36), (37) and (38). Hence $v(z)=\tilde{v}(z)$, which verifies the guess to our Bellman equation

$$
V(\mathscr{E} ; z)=v(z) \mathscr{E}^{1-\gamma}
$$

Separability: From (45) we have

$$
\left(e^{\prime}\left(\omega, \varepsilon ; z^{\prime}, z\right)\right)^{1-\gamma}=(1-\operatorname{div})^{1-\gamma}\left(R^{E}\left(\omega, \varepsilon ; z^{\prime}, z\right)\right)^{1-\gamma}
$$

so that

$$
E_{\omega, \varepsilon}\left[\left(e^{\prime}\left(\omega, \varepsilon ; z^{\prime}, z\right)\right)^{1-\gamma}\right]=(1-\operatorname{div})^{1-\gamma} E_{\omega, \varepsilon}\left[\left(R^{E}\left(\omega, \varepsilon ; z^{\prime}, z\right)\right)^{1-\gamma}\right]
$$

Since the utility is power utility, the certainty equivalence of $E_{\omega, \varepsilon}\left[\left(R^{E}\left(\omega, \varepsilon ; z^{\prime}, z\right)\right)^{1-\gamma}\right]$, denoted as $\Omega\left(z^{\prime}, z\right)$, follows as

$$
\begin{aligned}
\Omega\left(z^{\prime}, z\right) & =\max _{\left\{w_{c}, w_{i}, w_{b}, w_{d}\right\}}\left\{E_{\omega, \varepsilon}\left[\left(R^{E}\left(\omega, \varepsilon ; z^{\prime}, z\right)\right)^{1-\gamma}\right]\right\}^{\frac{1}{1-\gamma}} \\
& =\max _{\left\{w_{c}, w_{i}, w_{b}, w_{d}\right\}}\left\{E_{\omega, \varepsilon}\left[\left(w_{c}+R^{I} w_{i}+R^{B} w_{b}-R^{D} w_{d}-R^{x}\right)^{1-\gamma}\right]\right\}^{\frac{1}{1-\gamma}}
\end{aligned}
$$


subject to (41) and (42). Substituting (A2) into (A1) and using the definition of $\Omega\left(z^{\prime}, z\right)$ in (A3), we obtain (44).

C.3. Proof of Proposition 3. As $p^{\omega}$ increases, we first establish that the share of risky assets in total assets, $\frac{q^{r} I^{r}}{q^{r} I^{r}+q B^{\prime}}$ or $\frac{q^{r} I^{r}}{q^{r} I^{r}+q \widetilde{B}}$, increases; we then prove that the volume of risky assets, $q^{r} I^{r}$, increases as well.

Combining (41) and (42) and substituting them into (A3) transforms the optimization problem to

$$
\begin{aligned}
\Omega\left(z^{\prime}, z\right)=\max _{\left\{w_{c}, w_{i}, w_{b}, w_{d}\right\}}\left\{E _ { \omega , \varepsilon } \left[\left(R^{B}-\left(R^{B}-1\right) w_{c}+\left(R^{I}-R^{B}\right) w_{i}\right.\right.\right. \\
\\
\left.\left.\left.\quad-\left(R^{B}-R^{D}\right) w_{d}-R^{x}\left(w_{b}, w_{d} ; \omega\right)\right)^{1-\gamma}\right]\right\}^{\frac{1}{1-\gamma}}
\end{aligned}
$$

subject to $w_{d} \leq \kappa$ (with the Lagrangian multiplier $\phi_{d}$ ) and $w_{c} \geq 0$ (with the Lagrangian multiplier $\phi_{c}$ ). The first order condition with respect to $w_{c}$ gives

$$
\phi_{c}-\left(R^{B}-1\right) E_{\omega, \varepsilon}\left(R^{E}\right)^{-\gamma}\left[E_{\omega, \varepsilon}\left(R^{E}\right)^{1-\gamma}\right]^{\gamma /(1-\gamma)}=0 .
$$

It follows from $R^{B}>1$ that $\phi_{c}>0$, which implies that $w_{c}=0$.

Substituting $w_{c}=0$ and $w_{i}=1-w_{b}+w_{d}$ into (A4) reduces the optimization problem to

$$
\begin{aligned}
& \Omega\left(z^{\prime}, z\right) \\
& \quad=\max _{\left\{w_{b}, w_{d}\right\}}\left\{E_{\omega, \varepsilon}\left[\left(R^{I}+\left(R^{B}-R^{I}\right) w_{b}+\left(R^{I}-R^{D}\right) w_{d}-R^{x}\left(w_{b}, w_{d} ; \omega\right)\right)^{1-\gamma}\right]\right\}^{\frac{1}{1-\gamma}}
\end{aligned}
$$

subject to $w_{d} \leq \kappa$ and $\phi_{d}\left(\kappa-w_{d}\right)=0$. The first order condition with respect to $w_{b}$ gives

$$
\begin{aligned}
{\left[E_{\omega, \varepsilon}\left(R^{E}\right)^{1-\gamma}\right]^{\gamma /(1-\gamma)} E_{\omega, \varepsilon}\left(R^{E}\right)^{-\gamma} } & E_{\varepsilon}\left[R^{B}-R^{I}\right] \\
& -\left[E_{\omega, \varepsilon}\left(R^{E}\right)^{1-\gamma}\right]^{\gamma /(1-\gamma)} E_{\omega, \varepsilon}\left[\left(R^{E}\right)^{-\gamma} R_{b}^{x}\left(w_{b}, w_{d} ; \omega\right)\right]=0,
\end{aligned}
$$

where

$$
R_{b}^{x}\left(w_{b}, w_{d} ; \omega\right)=\frac{\partial R^{x}\left(w_{b}, w_{d} ; \omega\right)}{\partial w_{b}} .
$$

Noting from (46) that $R^{E}$ depends on both $\omega$ and $\varepsilon$, we simplify the above expression as

$$
\begin{gathered}
R^{B} E_{\varepsilon}\left[E_{\omega}\left(R^{E}\right)^{-\gamma}\right]-E_{\varepsilon}\left[R^{I} E_{\omega}\left(R^{E}\right)^{-\gamma}\right]=E_{\omega, \varepsilon}\left[\left(R^{E}\right)^{-\gamma} R_{b}^{x}\left(w_{b}, w_{d} ; \omega\right)\right] \\
\Longleftrightarrow \quad R^{B}-\frac{E_{\varepsilon}\left[R^{I} E_{\omega}\left(R^{E}\right)^{-\gamma}\right]}{E_{\varepsilon}\left[E_{\omega}\left(R^{E}\right)^{-\gamma}\right]}=\frac{E_{\omega, \varepsilon}\left[\left(R^{E}\right)^{-\gamma} R_{b}^{x}\left(w_{b}, w_{d} ; \omega\right)\right]}{E_{\varepsilon}\left[E_{\omega}\left(R^{E}\right)^{-\gamma}\right]},
\end{gathered}
$$


which leads to the asset-pricing condition between safe loans and risky investment:

$$
R^{B}-\underbrace{E_{\omega}\left[R_{b}^{x}\left(w_{b}, w_{d} ; \omega\right)\right]}_{\text {expected regulation cost }}=E_{\varepsilon}\left(R^{I}\right)-\underbrace{\left[-\frac{\operatorname{Cov}_{\varepsilon}\left(R^{I}, E_{\omega}\left(R^{E}\right)^{-\gamma}\right)}{E_{\varepsilon}\left[E_{\omega}\left(R^{E}\right)^{-\gamma}\right]}\right]}_{\text {default risk premium }} .
$$

The left-hand-side term represents the effective return to safe loans, expressed as the bank lending rate minus the expected regulation cost. The right-hand-side term is the expected return to risky investment, adjusted for the risk premium of default. Note that the risk premium is positive. The expected regulation cost is the expected marginal cost of meeting the LDR ceiling. Indeed, it is straightforward to show that this regulation cost is

$$
E_{\omega}\left[R_{b}^{x}\left(w_{b}, w_{d} ; \omega\right)\right]=\underbrace{\operatorname{Prob}(\theta \omega \geq \theta-\tilde{B} / \tilde{D})}_{\text {regulation risk }} r^{b} .
$$

By defining $L=\frac{w_{b}}{w_{d}}$ as the LDR, we can rewrite the bank's portfolio choice problem (A5) as

$$
\begin{aligned}
& \Omega\left(z^{\prime}, z\right) \\
= & \max _{L, w_{d}}\left\{E_{\omega, \varepsilon}\left[R^{I}+w_{d}\left[\left(R^{I}-R^{D}\right)-\left(R^{I}-R^{B}\right) L-R^{x}(L, 1 ; \omega)\right]\right]\right\}^{\frac{1}{1-\gamma}}
\end{aligned}
$$

subject to $w_{d} \leq \kappa$. The first order condition with respect to $L$ is

$$
R^{B}-\underbrace{E_{\omega}\left[R_{L}^{x}(L, 1 ; \omega)\right]}_{\text {expected liquidity cost }}=E_{\varepsilon}\left(R^{I}\right)-\underbrace{\left[-\frac{\operatorname{Cov}_{\varepsilon}\left(R^{I}, E_{\omega}\left(R^{E}\right)^{-\gamma}\right)}{E_{\varepsilon}\left[E_{\omega}\left(R^{E}\right)^{-\gamma}\right]}\right]}_{\text {default risk premium }},
$$

where

$$
R_{L}^{x}(L, 1 ; \omega)=\frac{\partial R^{x}(L, 1 ; \omega)}{\partial L} .
$$

This asset-pricing equation with respect to $L$ is an alternative expression of the previous asset-pricing equation with respect to $w_{b}$ (i.e., equation (47)). As one can see from below, this alternative expression makes our proof more transparent.

By definition,

$$
\frac{q^{r} I^{r}}{q^{r} I^{r}+q \widetilde{B}}=\frac{w_{i}}{w_{i}+w_{b}}=\frac{1}{1+w_{b} / w_{i}} .
$$

To prove that the share of risky assets increases with $p^{\omega}$ is equivalent to prove that $\frac{\partial w_{b} / w_{i}}{\partial p^{\omega}}<0$. When $p^{\omega}$ increases, $E_{\omega}\left[R_{L}^{x}(L, 1 ; \omega)\right]$ will increase. It follows from $(A 7)$ that the effective return to safe loans will decline relative to the effective return to risky investment. Hence, $w_{b} / w_{i}$ falls, implying that $\frac{q^{r} I^{r}}{q^{r} I^{r}+q \widetilde{B}}$ increases. 
We now prove that $\frac{\partial q^{r} I^{r}}{\partial p^{\omega}}>0$. We first establish the following lemma.

Lemma 1. With the low deposit rate such that

$$
R^{D}<R^{B}-r^{b} p^{\omega}
$$

the credit constraint $(26)$ or $w_{d} \leq \kappa$ is binding.

Proof. When $\omega=0$, there is no need to acquire additional deposits to meet the LDR ceiling. When $\omega=1$, however, the bank always needs to acquire additional deposits in order to meet the $\mathrm{LDR}$ requirement $L \leq \theta$. Accordingly,

$$
E_{\omega}\left[R^{x}(L, 1 ; \omega)\right]=r^{b} p^{\omega} L
$$

and

$$
E_{\omega}\left[R_{L}^{x}(L, 1 ; \omega)\right]=r^{b} p^{\omega}
$$

Define the leverage return as

$$
R^{L}=\left(R^{I}-R^{D}\right)-\left(R^{I}-R^{B}\right) L-R^{x}(L, 1 ; \omega) .
$$

We have

$$
E_{\omega, \varepsilon}\left[R^{L}(L ; \omega, \varepsilon)\right]=E_{\varepsilon}\left[(1-L)\left(R^{I}-R^{D}\right)+L\left(R^{B}-R^{D}\right)\right]-E_{\omega}\left[R^{x}(L, 1 ; \omega)\right]
$$

The first order condition for $w_{d}$ is

$$
E_{\omega, \varepsilon}\left[R^{L}(L ; \omega, \varepsilon)\right]-\left[-\frac{\operatorname{Cov}_{\varepsilon}\left(E_{\omega}\left(R^{E}\right)^{-\gamma}, R^{L}\right)}{E_{\varepsilon}\left[E_{\omega}\left(R^{E}\right)^{-\gamma}\right]}\right]=\widetilde{\phi}^{d}
$$

where $\widetilde{\phi}^{d}=\frac{\phi^{d}}{\left[E_{\omega, \varepsilon}\left(R^{E}\right)^{1-\gamma}\right]^{\frac{\gamma}{1-\gamma}} E_{\omega}\left[E_{\varepsilon}\left(R^{E}\right)^{-\gamma}\right]}$. The left-hand-side term is the effective expected return to leverage, adjusted for the default risk premium and the expected regulation cost.

To prove the credit constraint is binding, it is equivalent to show that the effective expected return to leverage is positive. That is, we need to show

$$
E_{\omega, \varepsilon}\left[R^{L}(L ; \omega, \varepsilon)\right]-\left[-\frac{\operatorname{Cov}_{\varepsilon}\left(E_{\omega}\left(R^{E}\right)^{-\gamma}, R^{L}\right)}{E_{\varepsilon}\left[E_{\omega}\left(R^{E}\right)^{-\gamma}\right]}\right]>0,
$$

which implies that $\widetilde{\phi}^{d}>0$ or $\phi^{d}>0$.

According to the definition of $R^{L}$,

$$
\frac{\operatorname{Cov}_{\varepsilon}\left(E_{\omega}\left(R^{E}\right)^{-\gamma}, R^{L}\right)}{E_{\varepsilon}\left[E_{\omega}\left(R^{E}\right)^{-\gamma}\right]}=\frac{(1-L) \operatorname{Cov}_{\varepsilon}\left(E_{\omega}\left(R^{E}\right)^{-\gamma}, R^{I}\right)}{E_{\varepsilon}\left[E_{\omega}\left(R^{E}\right)^{-\gamma}\right]} .
$$


Combining equation $(A 9)$ with equation $(A 10)$ leads to

$$
E_{\omega}\left[R^{x}(L, 1 ; \omega)\right]=L E_{\omega}\left[R_{L}^{x}(L, 1 ; \omega)\right] .
$$

Substituting both $(A 13)$ and $(A 14)$ into the left side of $(A 12)$ and reordering, we have

$$
\begin{aligned}
& E_{\omega, \varepsilon}\left[R^{L}(L ; \omega, \varepsilon)\right]-\left[-\frac{\operatorname{Cov}_{\varepsilon}\left(E_{\omega}\left(R^{E}\right)^{-\gamma}, R^{L}\right)}{E_{\varepsilon}\left[E_{\omega}\left(R^{E}\right)^{-\gamma}\right]}\right] \\
= & (1-L)\left\{E_{\varepsilon}\left(R^{I}\right)-\left[\frac{\operatorname{Cov}_{\varepsilon}\left(E_{\omega}\left(R^{E}\right)^{-\gamma}, R^{I}\right)}{E_{\varepsilon}\left[E_{\omega}\left(R^{E}\right)^{-\gamma}\right]}\right]\right\}+L\left\{R^{B}-E_{\omega}\left[R_{L}^{x}(L, 1 ; \omega)\right]\right\}-R^{D} \\
= & R^{B}-E_{\omega}\left[R_{L}^{x}(L, 1 ; \omega)\right]-R^{D},
\end{aligned}
$$

where the second equality comes from the asset-pricing condition $(A 7)$. Given $(A 10)$ and (A8), we have

$$
E_{\omega, \varepsilon}\left[R^{L}(L ; \omega, \varepsilon)\right]-\left[-\frac{\operatorname{Cov}_{\varepsilon}\left(E_{\omega}\left(R^{E}\right)^{-\gamma}, R^{L}\right)}{E_{\varepsilon}\left[E_{\omega}\left(R^{E}\right)^{-\gamma}\right]}\right]>0
$$

Hence, $\widetilde{\phi}^{d}>0$ or $\phi^{d}>0$

We are ready to prove $\partial\left(q^{r} I^{r}\right) / \partial p^{\omega}>0$. Because $q^{r} I^{r}=w_{i}(1-d i v) \mathscr{E}$, it is sufficient to prove that $\partial w_{i} / \partial p^{\omega}>0$ and $\partial \operatorname{div} / \partial p^{\omega} \leq 0$. Since $w_{i}+w_{b}=1+w_{d}$, we have $\frac{w_{i}}{w_{i}+w_{b}}=\frac{w_{i}}{1+w_{d}}=$ $\frac{w_{i}}{1+\kappa}$. Therefore, $\partial \frac{q^{r} I^{r}}{q^{r} I^{r}+q \widetilde{B}} / \partial p^{\omega}>0$ gives $\partial w_{i} / \partial p^{\omega}>0$.

We now need to prove $\partial \operatorname{div} / \partial p^{\omega} \leq 0$. The Euler equation associated with problem (44) can be written as

$$
\begin{aligned}
\operatorname{div}^{-\gamma}=\beta(1-\gamma)(1-\operatorname{div})^{-\gamma} E_{M}\left[E_{\omega \varepsilon}\left(R^{E}\right)^{1-\gamma} v\left(z^{\prime}\right) \mid z\right] \\
=\beta(1-\gamma)(1-\operatorname{div})^{-\gamma} E_{M}\left[v\left(z^{\prime}\right) \mid z\right] \\
\quad\left[p^{\omega} E_{\varepsilon}\left(R^{E}\left(\omega^{l}\right)\right)^{1-\gamma}+\left(1-p^{\omega}\right) E_{\varepsilon}\left(R^{E}\left(\omega^{h}\right)\right)^{1-\gamma}\right]
\end{aligned}
$$

Equation (A15) expresses div as an implicit function of $p^{\omega}$. Taking partial derivative of div with respect to $p^{\omega}$ and reorganizing the terms, we obtain

$$
\frac{\partial \operatorname{div}}{\partial p^{\omega}}=\frac{E_{\varepsilon}\left[\left(R^{E}\left(\omega^{l}\right)\right)^{1-\gamma}-\left(R^{E}\left(\omega^{h}\right)\right)^{1-\gamma}\right] \beta(1-\gamma) E_{M}\left[v\left(z^{\prime}\right) \mid z\right](1-\operatorname{div})^{-\gamma-1}}{-\gamma \operatorname{div}^{-\gamma-1}-\beta \gamma(1-\gamma) E_{M}\left[v\left(z^{\prime}\right) \mid z\right](1-\operatorname{div})^{-\gamma-1} E_{\omega \varepsilon}\left[\left(R^{E}\right)^{1-\gamma}\right]} .
$$

The denominator of $(A 16)$ is always negative, thanks to the concavity of the bank's utility function. ${ }^{31}$ For the numerator, whether it is positive or not depends on $\left(R^{E}\left(\omega^{l}\right)\right)^{1-\gamma}-$

\footnotetext{
${ }^{31}$ Note that $(1-\gamma) E_{M}\left[v\left(z^{\prime}\right) \mid z\right]>0$.
} 
$\left.\left(R^{E}\left(\omega^{h}\right)\right)^{1-\gamma}\right|_{\varepsilon} \gtrless 0$. Since $R^{E}\left(\omega^{l}\right)-\left.R^{E}\left(\omega^{h}\right)\right|_{\varepsilon}<0$ and given $\gamma \geq 1$, we have

$$
\left(R^{E}\left(\omega^{l}\right)\right)^{1-\gamma}-\left.\left(R^{E}\left(\omega^{h}\right)\right)^{1-\gamma}\right|_{\varepsilon} \geq 0 .
$$

Therefore, $\partial \operatorname{div} / \partial p^{\omega} \leq 0$. With $\partial w_{i} / \partial p^{\omega}>0$, we have $\partial\left(q^{r} I^{r}\right) / \partial p^{\omega}>0$. 


\section{REFERENCES}

Adrian, T., A. B. Ashcraft, and N. Cetorelli (2013): "Shadow Bank Monitoring," Staff Report 638, Federal Reserve Bank of New York.

Allen, F., Y. Qian, G. Tu, And F. Yu (2015): "Entrusted Loans, A Close Look at China's Shadow Banking System," Manuscript, University of Pennsylvania.

BA, S., M. Yan, And Y. WAng (2013): "Analysis of the Inference of Interest Rate Liberalization on Commercial Banks," Journal of Huazhong Normal University Humanities and Social Sciences (in Chinese), 52(4), 27-37.

Bianchi, J., And S. Bigio (2014): "Banks, Liquidity Management and Monetary Policy," Federal Reserve Bank of Minneapolis Research Department Staff Report 503.

Chang, C., K. Chen, D. F. Waggoner, and T. Zha (2015): "Trends and Cycles in China's Macroeconomy," NBER Macroeconomics Annual, 30.

Christiano, L. J., And D. Ikeda (2013): "Leverage Restrictions in a Business Cycle Model," Manuscript, Northwestern University.

Elliott, D. J., And A. R. K. Q. Yu (2015): "Shadow Banking in China: A Primer," Research paper, The Brookings Institution.

Gertler, M., and N. Kiyotaki (2010): "Financial Intermediation and Credit Policy in Business Cycle Analysis," in Handbook of Monetary Economics, ed. by B. M. Friedman, and M. Woodford, vol. 3, chap. 11, pp. 547-599. Elsevier B. V.

Hachem, K., And Z. M. Song (2015): "The Rise of China's Shadow Banking System," Manuscript, University of Chicago.

He, Q., L. Lu, and S. Ongena (2015): "Who Gains from Credit Granted Between Firms? Evidence from Inter-corporate Loan Announcements Made in China," Bank of Finland Discussion Paper 1.

Ivashina, V., And D. Scharfstein (2010): "Bank Lending During the Financial Crisis of 2008," Journal of Financial Economics, 97, 319-338.

Jiménez, G., S. Ongena, J.-L. Peydró, and J. Saurina (2014): "Hazardous Times for Monetary Policy: What do Twenty-three Million Loans Say About the Impact of Monetary Policy on Credit Risk-Taking?," Econometrica, 82(2), 463-505.

Kashyap, A. K., And J. C. Stein (2000): "What Do a Million Observations on Banks Say About the Transmission of Monetary Policy?," American Economic Review, 90, 407-428. 
Nakamura, E., J. Steinsson, and M. Liu (2014): "Are Chinese Growth and Inflation Too Smooth? Evidence from Engel Curves," Unpublished Manuscript, Columbia University.

Qian, X., AND X. Li (2013): "Operating Mechanism and Guarding Financial Risks of Entrusted Loans: Stemming from the Public Data of Listed Companies in China from 2004-2013," Enterprise Development (in Chinese), 10, 125-134.

Emory University; Emory University; Federal Reserve Bank of Atlanta, Emory UniverSITY, AND NBER 